\title{
EL REINO UNIDO Y LA UNIÓN EUROPEA: INICIO Y FIN DE UNA RELACIÓN ATORMENTADA
}

\author{
ANTONIO BAR CENDÓN \\ Catedrático de Derecho Constitucional \\ Catedrático Jean Monnet «ad personam» \\ Universidad de Valencia
}

SUMARIO

I. Introducción. II. El inicio de la relación. III. El desarrollo de la relación: la incómoda posición del Reino Unido en la Unión Europea. IV. El último intento de acomodo: Cameron y el Consejo Europeo de febrero de 2016. V. La ruptura de la relación: el referéndum de junio de 2016. VI. El marco jurídico de la separación: el art. 50 del TEU. VII. Conclusión

\section{INTRODUCCIÓN}

Cuando estaba a punto de cumplirse el 45 aniversario de su ingreso en las Comunidades Europeas, el Reino Unido decidió salir de la Unión Europea. Entre un momento y otro ha habido una relación difícil; relación que ha tenido una dimensión muy positiva para las dos partes, pero también una dimensión negativa. En realidad, el Reino Unido (en adelante RU) nunca se adaptó bien a la filosofía que inspiró en su momento la creación de las Comunidades Europeas (en adelante CCEE) y de la Unión Europea (en adelante UE), después. El RU no quiso entrar en las CCEE en su mismo inicio precisamente porque no compartía esa filosofía y, si lo hizo unos años más tarde, fue porque lo necesitaba económicamente, no porque hubiese cambiado sus planteamientos básicos a este respecto. Pero, tras su entrada en las CCEE, el RU nunca buscó adaptarse plenamente a las condiciones y términos que inspiraban y gobernaban las CCEE, sino, más bien al contrario, trató siempre de que las CCEE se adaptasen a sus propias condiciones y exigencias. Las CCEE y la UE pretendían el establecimiento de una unión política y económica en Europa; el RU, en cambio, buscaba sólo el establecimiento de un mercado común. 
A lo largo de todos estos años, la UE fue cediendo y condicionando su proceso de integración interna a las exigencias del RU. La estructura y dinámica de las CCEE, primero, y de la UE, después, sus competencias, su financiación, la política económica y monetaria, las ampliaciones a otros países, las relaciones exteriores, la política de defensa, etc., son hoy en día como el RU ha querido que fueran, y si no se ha ido más lejos en el proceso de integración y éste no se ha hecho de una manera más coherente y democrática es precisamente porque el RU lo ha impedido. El RU ha hecho todo lo posible para evitar el refuerzo de las instituciones europeas, como instituciones autónomas y democráticas. El RU siempre ha preferido reforzar el papel de los Estados en el proceso decisorio de la UE y en el control de las instituciones europeas, más que desarrollar el ejercicio autónomo y eficiente del poder por parte de las mismas. Y, en este sentido, el RU siempre ha visto la profundización de la democracia en el seno de la UE —y el aumento de su legitimidad - como el resultado del refuerzo de la participación de los Parlamentos nacionales en el proceso decisorio de ésta, y no como el resultado del fortalecimiento del papel del Parlamento Europeo, que es la institución representativa propia de la UE.

En realidad, podría decirse que, movido por sus intereses económicos, el RU pretendió alterar los términos de un largo proceso histórico, en cuyo inicio ni siquiera quiso estar involucrado, y, al final, la cosa no salió bien, las dos partes quedaron insatisfechas y finalmente la relación se rompió. Quizá la visión más completa y realista de este proceso histórico la tuvieron precisamente los dos grandes líderes políticos que lo promovieron, basados precisamente en la experiencia de tener que dirigir a sus respectivos países en momentos dramáticos de su historia: el Primer Ministro británico Winston Churchill y el Presidente francés Charles De Gaulle. Los dos, verdaderamente, han marcado el devenir del siglo xx en Europa. De la visión del General De Gaulle nos ocupamos más adelante en este trabajo (en la sección II), baste aquí, pues, referirnos brevemente a la visión de Churchill.

Winston Churchill, en un celebrado discurso en la Universidad de Zúrich, el 19 de septiembre de 1946, proponía, para resolver el problema de la atormentada Historia del continente europeo, la creación de unos Estados Unidos de Europa. Sin embargo - en su visión - el Reino Unido no debería participar en este proceso, sino que debería apoyarlo desde fuera, al igual que deberían hacerlo también los Estados Unidos de América y la Unión Soviética. En su visión, este proceso de integración política debería ser liderado por Francia y Alemania, países que precisamente habían estado en el origen de las grandes confrontaciones que habían ensangrentado Europa en los últimos cien años. Así, decía Churchill: «[...] debemos recrear la familia europea en una estructura regional denominada, puede ser, los Estados Unidos de Europa [...] En esta tarea urgente, Francia y Alemania deben tomar juntas la dirección. Gran Bretaña, la Commonwealth británica, la ponderosa América —y, yo creo, la Rusia Soviética [...] — deben ser los amigos y los promotores de la nueva Europa y deben defender su derecho a vivir». 
A lo que añadía: «El primer paso en la recreación de la familia europea debe ser una asociación entre Francia y Alemania. Sólo de esta manera podrá Francia recuperar el liderazgo moral y cultural de Europa. No habrá un renacer de Europa sin una espiritualmente grande Francia y una espiritualmente grande Alemania».

$Y$, verdaderamente, Churchill pensaba entonces en una unión política de Europa, superadora de las viejas estructuras estatales, y no en una mera cooperación económica, como luego los líderes políticos británicos quisieron ver. Así, decía: «La estructura de los Estados Unidos de Europa será de tal manera que convierta la fuerza material del Estado individual en menos importante. Las naciones pequeñas contarán tanto como las grandes y obtendrán su prestigio de su contribución a la causa común» ${ }^{1}$.

Sin embargo, el proceso europeo de integración, no siguió las líneas trazadas por Churchill, ni en lo que se refiere a la participación del propio RU en este proceso, ni en lo que se refiere al camino seguido por los Estados continentales europeos en su integración política y económica. En lo que se refiere a la participación del RU, éste decidiría finalmente no quedarse al margen e incluirse en el proceso europeo de integración, si bien buscando sólo la integración económica - y ni siquiera plena - y rechazando siempre la integración política. Y, en lo que se refiere a los Estados continentales europeos, éstos decidieron cambiar el orden de las cosas y buscar, en primer lugar, la plena integración económica, dejando para más tarde el proceso de integración política, sobre la base de la consolidación de la primera.

A pesar de todo, el seminal discurso de Churchill es fundamental para comprender la posición del Reino Unido en la Unión Europea y para comprender también la decisiva posición de Francia y de Alemania en este peculiar proceso de integración. Pero, al mismo tiempo, el discurso de Churchill sirve igualmente para comprender el carácter escalonado, secuencial, de este proceso de integración; si bien es verdad que los Estados participantes decidieron — quizá con razón- alterar el orden de esta secuencia y poner primero la integración económica y luego, al final del proceso y como consecuencia lógica, la integración política (visión «funcionalista») ${ }^{2}$.

Este trabajo trata de describir y analizar cómo se ha producido este proceso de relación del RU con las CCEE primero, y con la UE, después, desde la solicitud del RU de adhesión a las CCEE, en agosto 1961, hasta el comienzo de las negociaciones sobre la separación de la UE, en junio de 2017. Es decir, se trata de estudiar un proceso que va de las negociaciones de adhesión a las negociaciones de separación, pasando por la atormentada pertenencia a la UE y la ruptura final que supuso el referéndum del Brexit, de junio de 2016.

1 Traducción propia del original inglés: Churchill, W., «United States of Europe». University of Zurich, September 19, 1946 (The Churchill Centre, Speeches 1946-1963 - Elder-Statesman); en: http:// www.winstonchurchill.org/resources/speeches/1946-1963-elder-statesman/united-states-of-europe.

2 Rosamond, B., Theories of European Integration (London: Macmillan 2000), pp. 31 ss. 


\section{EL INICIO DE LA RELACIÓN}

Tras un largo y difícil proceso, el RU ingresó en las CCEE el 1 de enero de 1973, junto con Dinamarca e Irlanda. El Tratado de Adhesión se había firmado en Brusleas un año antes, el 22 de enero de 1972. Noruega era también una parte de este acuerdo de adhesión, pero el gobierno noruego decidió después someter el acuerdo a referéndum y los ciudadanos noruegos lo rechazaron, el 25 de septiembre de 1972 .

El proceso que llevó a este resultado se inició en 1961, cuando el Primer Ministro conservador Harold Macmillan presentó la primera solicitud de adhesión a las CCEE, el 9 de agosto de aquel año. Antes, cuando se iniciaron los primeros movimientos que conducirían a la Declaración Schumann (9 de mayo de 1950) y a la creación de la primera Comunidad - la Comunidad Europea del Carbón y del Acero (CECA)—, justo un año después, ni el Primer Ministro laborista Clement Attlee (1945-1951), ni Winston Churchill en su segundo Gobierno (1951-1955), ni el Primer Ministro conservador que le siguió, Anthony Eden (1955-1957), ni tampoco el laborista Harold Macmillan en su primer Gobierno (1957-1959), quisieron unirse al proceso de integración que comenzaba entonces en Europa. Tanto en la creación de la CECA (18 de abril de 1951), como en la creación de la Comunidad Económica Europea (CEE) y de la Comunidad Europea de la Energía Atómica (CEEA), el 25 de marzo de 1957, el Reino Unido fue invitado a las negociaciones iniciales, pero declinó la invitación a formar parte de estas asociaciones. El RU no quiso participar en los contactos que precedieron a la Declaración Schumann y, en abril de 1951, Francia llegó a enviarles un ultimátum, 24 horas antes de la conclusión formal de las negociaciones que condujeron a la creación de la CECA, para que se uniesen al proceso, pero el RU prefirió mantenerse al margen. En 1955, cuando se iniciaron las negociaciones para la creación de la CEE y de la CEEA, el RU llegó a enviar un representante a la Conferencia de Messina, pero finalmente decidió reiterarlo ${ }^{3}$. Muy al contrario, el RU promovió la creación de una asociación económica alternativa a la CEE, la European Free Trade Association (EFTA), formada entonces por siete Estados (Stockholm Convention, de 4 de enero de 1960). Se hablaba entonces de «the outer seven», frente a los «inner six». La percepción negativa del proceso de integración que comenzaba entonces en el continente europeo era, pues, inicialmente compartida por conservadores y laboristas.

Sin embargo, una serie de nuevas circunstancias económicas y políticas forzaron al conservador Harold Macmillan a cambiar de opinión y a solicitar el ingreso en las Comunidades Europeas el 9 de agosto de 1961, tras la formación

3 HM Government, «The EEC and Britain's late entry» (National Archives, United Kingdom Government, Cabinet Papers, n.d.), en: http://www.nationalarchives.gov.uk/cabinetpapers/themes/eec-britains-late-entry.htm. 
de su segundo Gobierno (1959-1963). El RU había frenado su crecimiento económico, mientras que, muy al contrario, los países miembros de las CCEE crecían a un ritmo acelerado en el marco de una asociación que se consolidaba y reforzaba su «mercado común». Por otra parte, la EFTA no producía los resultados económicos esperados y, además, era un mercado limitado de sólo 90 millones de personas, frente a los casi 300 millones de las CCEE. A mayor abundamiento, la resolución de la crisis que siguió a la nacionalización del Canal de Suez y la forzada retirada del RU de la zona, supuso la pérdida de su papel de potencia dominante, no sólo en el Oriente Medio sino también, en general, en el conjunto de las relaciones internacionales; papel en el que el RU sería inmediatamente sustituido por los Estados Unidos de América. A ello ha de añadirse también el comienzo del fin del imperio británico, con el acceso a la independencia de las antiguas colonias, que tiene lugar en los años sesenta del siglo pasado, en la mayoría de los casos. Con este panorama, el RU no podía correr el riesgo de quedarse marginado, retrasado económicamente con respecto a los países desarrollados del continente - principalmente Francia y Alemania- y debilitado políticamente en el nuevo contexto de las relaciones internacionales ${ }^{4}$.

Sin embargo, la solicitud británica fue rechazada por el Presidente francés, Charles de Gaulle, en solemne rueda de prensa, el 14 de enero de 1963, y por el Consejo pocos días después, el 29 de enero. Para de Gaulle, la estructura económica del Reino Unido era incompatible con la de la Comunidad Económica Europea y, muy específicamente su régimen agrícola, dependiente de las importaciones de sus colonias y de Américas.

Pero no era sólo la estructura económica de los Seis, o la agricultura francesa la mayor preocupación de De Gaulle, sino las consecuencias políticas de la entrada de RU y el cambio en la sustancia política de las CCEE que tal entrada podría suponer si las Comunidades se adaptasen a las exigencias del RU y de los Estados de la EFTA que con él querrían entrar en similares términos. Consecuencias entre las que se encontraría el abrir las puertas a la influencia de los Estados Unidos y la sumisión de todo el proceso de integración europeo y a los intereses norteamericanos. Así, decía el Presidente francés: «[...] hay que admitir que la entrada de Gran Bretaña primero y luego la de estos Estados cambiaría por completo el conjunto de los ajustes, los acuerdos, las compensaciones, las reglas que se han establecido ya entre los seis [...] Eso sería entonces otro mercado común del que deberíamos considerar su construcción. Pero [...] no se parecería en nada al que han construido los seis. Por otra parte, esta Comunidad, aumentando de esta

4 HM Government, «The EEC and Britain's late entry», cit; Rubinstein, W. D., Twentieth-Century Britain: A Political History (Basingstoke, UK: Palgrave Macmillan, 2003), pp. 232 ss.

5 De Gaulle, C; «Conférence de presse du 14 janvier 1963 (sur l'entrée de la Grande-Bretagne dans la CEE)», en De Gaulle, C;, Paroles Publiques (Institut national de l'audiovisuel, INA, Réf. 00085: http:// fresques.ina.fr/de-gaulle/fiche-media/Gaulle00085/conference-de-presse-du-14-janvier-1963-sur-l-entreede-la-grande-bretagne-dans-la-cee.html. 
manera, vería como se le plantearían todos los problemas de las relaciones económicas con todo tipo de otros Estados y principalmente con los Estados Unidos. [...] por ello, en definitiva, parecería una Comunidad Atlántica colosal bajo la dependencia y dirección americana, que habría de absorber pronto a la Comunidad de Europa. [...] pero eso no es en absoluto lo que ha querido hacer y que ha hecho Francia, que es una construcción propiamente europea» ${ }^{6}$.

La posición del general De Gaulle hay que entenderla, además, desde el contexto de los intereses de la propia Francia - aunque así no fuese confesado en las declaraciones del General-, más allá de los intereses de los Seis. En aquel momento, Francia vivía un proceso de reafirmación y consolidación nacional y del sistema de la V República: la guerra de Argelia se había acabado, el general De Gaulle había ganado el referéndum del 28 de octubre de 1962, que introdujo la elección del Presidente de la República por sufragio universal (él mismo sería el primer Presidente elegido por sufragio universal en las elecciones presidenciales de diciembre de 1965, tras la elección de Napoleón III en diciembre de 1848), su partido, de reciente creación — la Union pour la Nouvelle République (UNR)—, había ganado las elecciones legislativas de noviembre de 1962 con una amplia mayoría, y, en fin, el Presidente De Gaulle acababa de dar un portazo al Presidente norteamericano Kennedy en la Conferencia de Nassau, de diciembre de 1962, en su pretensión de someter el armamento nuclear de todos los miembros de la OTAN al mando único de los americanos y la renuncia a construir nuevas ojivas termonucleares; pretensión a la que sí había accedido el RU. Ello le permitía a Francia asegurar una fuerza de disuasión independiente y reforzar así su posición como potencia internacional ${ }^{7}$.

Apenas un año después del primer veto francés, Macmillan renunció al cargo de Primer Ministro (18 de octubre de 1963) y fue sustituido por Alexander Douglas-Home, por un breve período de tiempo (1963-1964). El conservador Douglas-Home no reiteró la solicitud de adhesión, como tampoco lo hizo el Primer Ministro que le siguió en el cargo, el laborista Harold Wilson, durante su primer mandato (1964-1966). Sin embargo, la actitud de ambos partidos había cambiado y era en ese momento, de manera general, favorable a la adhesión del RU a las CCEE. Así, en las elecciones del 31 de marzo de 1966, los laboristas llevaban ya en su programa electoral el objetivo de la adhesión, y el 10 de mayo de 1967 el Gobierno británico presentaba de nuevo su solicitud de adhesión, ahora de la mano de los laboristas. Como el Primer Ministro Wilson había explicado poco antes, en una conferencia de su partido, y volvería a hacerlo también en la Cámara de los Comunes, el 2 de mayo de 1967, «la decisión del Gobierno ha sido motivada por amplias consideraciones de política económica»; sin embargo, como él

6 Traducción propia del original francés: DE GAULle, C; «Conférence de presse du 14 janvier 1963», cit.

7 Dalloz, J; La France et le monde depuis 1945, Armand Colin, Paris, 2a ed., 2014; Milza, P; BersTEIN, S., Histoire de la France au XXe siècle. 1958 à nos jours, Perrin, Paris, 2009. 
mismo añadía, «pero, cualesquiera que fueren los argumentos económicos [...] el propósito del Gobierno deriva, sobre todo, de nuestro reconocimiento de que Europa se enfrenta ahora con la oportunidad de caminar hacia la unidad política y que nosotros podemos, y en verdad debemos, jugar plenamente nuestro papel en ello. [...] Juntos podemos asegurar que Europa juegue en los asuntos internacionales la parte del papel que Europa no está jugando en la actualidad $»^{8}$.

Sin embargo, una vez más, la solicitud británica se encontró con la oposición frontal del Presidente francés Charles De Gaulle, quien expresó su rechazo de la candidatura británica en dos conferencias de prensa consecutivas, el 16 de mayo de 1967, sólo unos días después de la presentación de la solicitud de adhesión, y el 27 de noviembre de 1967, en el marco de una amplia y solemne rueda de prensa, en la que, además, el Presidente francés se ocupó también de otros asuntos importantes del momento, como la Guerra de los Seis Días, entre los Estados árabes e Israel, la guerra de Vietnam, o la independencia de Québec. Los argumentos de De Gaulle insistían, una vez más, en lo ya dicho en $1963^{9}$.

Sería necesaria la renuncia de De Gaulle a la presidencia francesa (el 28 de abril de 1969), para que el panorama cambiase radicalmente. En realidad, Francia se encontraba sola en su veto al RU, dado que los demás estados miembros se habían manifestado favorables a la adhesión, tanto en 1963 como en 1968. Así, la llegada Georges Pompidou a la presidencia de la República francesa, el 15 de junio de 1969, y el nombramiento como Primer Ministro del RU del conservador Edward Heath justo un año más tarde, el 19 de junio de 1970, permitieron el desbloqueo de la situación. El diálogo Pompidou-Heath permitió el reinicio de las negociaciones formales el mismo mes de junio de $1970 \mathrm{y}$, tras dos años de costosos acuerdos, el tratado de adhesión se firmó el 22 de enero de 1972. Tanto Irlanda, como Dinamarca y Noruega, que habían negociado en paralelo sus respectivos acuerdos de adhesión, sometieron la decisión al referéndum de sus ciudadanos, siendo el voto obtenido favorable en los casos de Irlanda (83\% de los votos) y de Dinamarca (63.5\% de los votos), mientras que el resultado fue negativo en el caso de Noruega ( $53.5 \%$ de los votos en contra).

El Gobierno Heath, sin embargo, no sometió el acuerdo de adhesión a referéndum. En realidad, la adhesión a las Comunidades Europeas era el punto más importante de su programa electoral en las elecciones del 18 de junio de $1970 \mathrm{y}$, por ello, aplicando la doctrina constitucional tradicional de la soberanía

8 Traducción propia del original inglés: Wilson, H., «Statement by Harold Wilson on the United Kingdom's application for membership to the EC» (House of Commons, 2 May 1967); en: Centre Virtuel de la Connaissance sur l'Europe (CVCE), Université du Luxembourg: http://www.cvce.eu.

9 De Gaulle, C., «Conférence de presse de Charles de Gaulle sur l'adhésion du Royaume-Uni aux Communautés européennes (16 mai 1967)», Centre Virtuel de la Connaissance sur l'Europe (CVCE), Université du Luxembourg: http://www.cvce.eu; De Gaulle, C., «Conférence de presse de Charles de Gaulle: le second veto (27 novembre 1967)», Centre Virtuel de la Connaissance sur l'Europe (CVCE), Université du Luxembourg: http://www.cvce.eu. 
parlamentaria y basado en el respaldo popular obtenido en las elecciones, se limitó a someter la cuestión al debate y ratificación del Parlamento. Debate que duró siete días (21-28 de octubre de 1971), lo que, añadido a la relevancia de la cuestión, permitió al entonces líder de la oposición, Harold Wilson, denominarlo, «the Great Debate» ${ }^{10}$. El resultado del debate y la decisión de los Comunes fueron claramente favorables a la adhesión a las CCEE: votaron a favor 356 diputados (54.8\%), y 244 lo hicieron en contra (37.5\%). De esta manera, el 31 de diciembre de 1972 el RU abandonó la EFTA y el 1 de enero de 1973 ingresó en las CCEE.

La decisión era verdaderamente histórica. El RU abandonaba así su tradicional aislamiento y se unía a un proceso de integración que — se sabía - no era meramente económico, sino que tenía también una creciente dimensión política. Se trataba de adherirse a «une union sans cesse plus étroite entre les peuples européens» (una unión cada vez más estrecha entre los pueblos europeos), como establecía entonces el preámbulo del Tratado de la Comunidad Económica Europea. Y así lo reconoció el Primer Ministro Edward Heath, de manera expresa, en aquel relevante debate parlamentario de octubre de 1971: «No puedo resaltar más la importancia del voto que vamos a realizar esta noche, la importancia de la cuestión, la escala y relevancia de la decisión y el impacto que la misma va a tener tanto dentro como fuera de Gran Bretaña [...] Esta noche el mundo entero está observando Westminster, esperando ver si vamos a decidir que la Europa Occidental debería avanzar en el camino de la unidad real, o si el Parlamento británico, que ahora tiene la oportunidad, no por primera vez, pero posiblemente por última vez en mucho años, rechazará la oportunidad de crear una Europa unida» ${ }^{11}$.

Sin embargo, la cuestión estaba muy lejos de quedar cerrada y, como se puso de manifiesto en el debate parlamentario de octubre de 1971, no se trataba sólo de problemas de índole económica, sino de asuntos de verdadera transcendencia política y constitucional. Y entre ellos, de manera principal, se encontraba la cuestión de la sumisión de la soberanía del Parlamento británico a un poder legislativo superior y foráneo —el de las Comunidades Europeasaunque fuese sólo en los campos en los que se trasladaba esa competencia a las Comunidades.

Así, tras las elecciones generales de 28 de febrero de 1974, el laborista Harold Wilson volvió al gobierno, si bien con una escasa mayoría, lo que le obligó a disolver el Parlamento unos meses más tarde, con la intención de ampliar su respaldo en la cámara. Las nuevas elecciones tuvieron lugar el 10 de octubre de 1974 y, en esta ocasión, Wilson sí logró la mayoría, aunque sólo por tres escaños (Wilson dimitiría el 5 de abril de 1976, antes de finalizar su mandato). Pero, lo que

10 HC Deb 28 October 1971 vol. 823 c 2080.

11 Traducción propia del original inglés: HC Deb 28 October 1971 vol. 823 cc 2202-2203. 
interesa resaltar aquí es que, en los dos programas electorales presentados en las respectivas elecciones, el partido laborista prometió conseguir una renegociación de los términos de la adhesión del RU a las CCEE y convocar con posterioridad un referéndum sobre si el RU debería permanecer en las CCEE, en los términos del nuevo acuerdo ${ }^{12}$.

Las nuevas negociaciones se iniciaron, a nivel ministerial, el 1 de abril de 1974 y concluyeron un año más tarde con el acuerdo conseguido en la cumbre de Paris, de 9-10 de diciembre de 1974, y en el Consejo Europeo de Dublín, de 10-11 de marzo de 1975. Básicamente, el acuerdo consistió en dos cosas: En primer lugar, se introdujo un mecanismo corrector en el presupuesto de las Comunidades. Este acuerdo supuso que el RU recibiese una devolución anual de una media aproximada de 125 millones de libras por año (de esta manera, Wilson conseguía de las CCEE el primer «cheque británico», justo diez años antes de que Margaret Thatcher consiguiese el suyo, en 1985). Y, en segundo lugar, con respecto a las importaciones de productos frescos y otros alimentos provenientes de los Estados de la Commonwealth, se acordó extender el período transitorio previsto en el Tratado de Adhesión de 1977 y en su el Protocolo n 18, de 1977 a 1980 .

Con respecto a las demás exigencias del Gobierno británico, el Consejo Europeo decidió dejar la cuestión en las manos de la Comisión Europea, para que ésta fuese quien hiciese las correspondientes propuestas de modificación que el Consejo debería adoptar en futuras reuniones. En este sentido, no deja de sorprender el triunfalismo con el que el Primer Ministro Wilson informó a la Cámara de los Comunes del acuerdo conseguido, el 12 y el 18 de marzo de 1975, y el detalle y extensión con el que se refirió al mismo — principalmente en su segunda intervención-, como si todas las exigencias británicas hubiesen sido plenamente conseguidas $^{13}$. Y en la misma línea se expresaba el panfleto que el Gobierno publicó para el referéndum ${ }^{14}$. En realidad, las cosas no fueron exactamente así, y muchos de los puntos relevantes de las exigencias británicas no llegaron ni siquiera a ser discutidos, ni en la cumbre de París, de diciembre de 1974, ni en el Consejo Europeo de Dublín, de marzo de 1975. Así, por ejemplo, todo lo referido a la supresión del IVA en productos de primera necesidad, como los alimentos; a la política impositiva; a la política industrial; a la política de desarrollo regional, principalmente en Escocia y en Gales; y, desde luego, ni se debatió ni se acordó nada en relación con el papel legislativo y la soberanía del Parlamento británico en el seno de las Comunidades, dado que ello hubiese supuesto una alteración sustantiva de los tratados de las CCEE.

12 Miller, V., The 1974-75 UK Renegotiation of EEC Membership and Referendum (London: House of Commons, Briefing Paper $n^{\circ} 7253,13$ July 2015), p. 6.

13 Véase su intervención parlamentaria en HC Deb 12 March 1975 vol. 888 cc 509-522, y en HC Deb 18 March 1975 vol. 888 cc 1456-1480.

14 Wilson, H., Britain's New Deal in Europe (Issued by HM Government, London 1975). 
En todo caso, el referéndum sobre la permanencia del RU en las CCEE se celebró el 5 de junio de 1975. La pregunta fué «Do you think the United Kingdom should stay in the European Community (the Common Market)?» (¿Cree que el Reino Unido debe permanecer en la Comunidad Europea (el Mercado Común)?). La participación fue alta (64.03\%) y el Sí (67.2\%) fue claramente mayoritario con respecto al No $(32.8 \%)^{15}$.

\section{EL DESARROLLO DE LA RELACIÓN: LA INCÓMODA POSICIÓN DEL REINO UNIDO EN LA UNIÓN EUROPEA}

\section{Una atormentada integración}

Sin embargo, el referéndum de junio de 1975 no sirvió verdaderamente para resolver la cuestión europea. A diferencia de los Estados continentales, el Reino Unido no entró en las CCEE por su vocación integracionista ni para resolver los problemas que el nacionalismo había traído consigo en el continente europeo, tanto en el interior de los propios Estados, como en sus relaciones internacionales. Entró, en realidad, por necesidad: por necesidad económica, para superar una etapa difícil de crisis y para no quedarse retrasado ante el rápido progreso económico de los Seis; y por necesidad política, para no quedarse aislado en un contexto internacional en el que su papel era cada vez menor. En este sentido, el nacionalismo, el orgullo nacional, nunca fue un problema a superar en el RU, muy al contrario, es la verdadera espina dorsal del ser británico ${ }^{16}$, y de aquí que la relación del RU con los Seis primero y con la Unión Europea después, se basase siempre en el recelo, en el temor a perder su identidad nacional y su condición de Estado soberano. En este sentido, el RU nunca quiso jugar el papel de líder político de la Unión y de competir en ello con Francia y Alemania; muy al contrario, el RU se ha limitado siempre a operar como un freno, como un contrapeso que ha tratado de limitar siempre la velocidad y reducir la intensidad del proceso de la integración europea.

Así, tanto para el RU como para las CCEE, primero, y la UE después, el camino realizado en los años que siguieron a la adhesión y hasta el referéndum de 2016, fue una verdadera carrera de obstáculos. El primer obstáculo serio fue el referéndum de 1975 y la renegociación del Tratado de Adhesión de 1972, como

15 Véase una detallada descripción del referéndum de 1975 en: Miller, V., The 1974-75 UK Renegotiation, cit.

16 En su transcendente discurso del 17 de enero de 2017, Theresa May lo decía con franqueza: «one of the reasons that Britain's democracy has been such a success for so many years is ... the strength of our identity as one nation, the respect we show to one another as fellow citizens, and the importance we attach to our institutions» (The government's negotiating objectives for exiting the EU: PM May speech («Lancaster House» speech) 17 January 2017). 
hemos descrito en páginas anteriores. El Segundo obstáculo fue la crisis financiera interna que se cerró en el Consejo Europeo de Fontainebleau (25-26 de junio de 1984) y con el acuerdo sobre el «cheque británico» y la reforma del sistema de recursos propios de las Comunidades, de mayo de 1985, forzados por la Primera Ministra británica Margaret Thatcher. El acuerdo pretendía compensar al RU un «Member State bearing an excessive budgetary burden in relation to its relative prosperity»— por la diferencia entre el porcentaje de su contribución a los presupuestos comunitarios a través del IVA y el porcentaje del dinero recibido de los mismos; compensación que se obtuvo de introducir una corrección del $66 \%$ de la contribución por IVA del RU al presupuesto anual de las $\mathrm{CCEE}^{17}$.

El problema era que una parte importante de los ingresos por IVA se dedicaba a la financiación de la agricultura - lo que suponía aproximadamente un 70\% del presupuesto de la Comunidad Europea en aquel momento-, pero el RU tenía un sector agrícola muy pequeño, sobre todo en comparación con otros Estados como Francia, Italia o Alemania, lo que implicaba que recibía una cantidad anual del presupuesto comunitario mucho menor que la que recibía Francia, sobre todo, pero también los otros dos países grandes, por subvenciones a su sector agrícola. La corrección financiera acordada supuso que el RU recibiría una compensación de aproximadamente 3,8 billones de euros por año. (En 2014, esta compensación alcanzó la cifra de 6,1 billones de euros, reduciendo la contribución global del RU al presupuesto comunitario en un 35\% - un total de 11,34 billones de euros-, siendo así la cuarta contribución nacional $)^{18}$. El «cheque británico» de Margaret Thatcher fue, por tanto, la segunda compensación económica conseguida por el RU, tras la conseguida por Harold Wilson en 1975.

El tercer obstáculo que esta relación RU-UE hubo de superar fueron las limitaciones que el RU impuso desde el mismo momento de la creación de la Unión Europea. La UE era un paso adelante en el proceso de integración demasiado grande como para poder ser aceptado sin ningún tipo de freno o restricción; y así es como el principio de subsidiariedad fue introducido en el Tratado de Maastricht (Arts. B y G.5 del Tratado de Maastricht, que introducen el nuevo Art. 3B del reformado Tratado de la Comunidad Europea). El principio no era nuevo, de hecho, había sido introducido ya por el Art. 25 del Acta Única Europea de 1986, que modifica el Art. $130 \mathrm{R}$ del TCEE, referido a la protección del medio ambiente ${ }^{19}$. Esta previsión se incluyó entonces en el Tratado a exigencia de

17 Council Decision of 7 May 1985 on the Communities' system of own resources, 85/257/EEC, Euratom (Article 3).

18 European Parliament, United Kingdom's Renegotiation of its Constitutional Relationship with the EU: Agenda, Priorities and Risks (European Parliament, Directorate General for Internal Policies, Policy Department C: Citizens' Rights and Constitutional Affairs, December 2015).

19 Art. 130 R del TCEE: «La Comunidad actuará, en los asuntos de medio ambiente, en la medida en que los objetivos contemplados en el apartado 1 puedan conseguirse en mejores condiciones en el plano comunitario que en el de los Estados miembros considerados aisladamente». (Esta previsión desapareció del Art. 130 R TCE precisamente en la reforma que realizó el Tratado de Maastricht, que pasó a regular la 
Dinamarca, dado que este país no quería que la competencia de la Comunidad en materia de medio ambiente - que entonces se introducía en el Tratado por primera vez- supusiese la adopción de una normativa en esta materia que pusiese en cuestión la normativa más exigente adoptada ya por Dinamarca. En 1992, en cambio, el principio de subsidiariedad fue simplemente una concesión a la exigencia del RU de disponer de un freno con el que limitar el crecimiento del proceso europeo de integración y el desarrollo competencial de la Unión que entonces se creaba. La subsidiariedad fue, en verdad, el precio político que los demás Estados miembros hubieron de pagar al RU para que su Primer Ministro, John Major, firmase el Tratado de Maastricht y aceptase la creación de la Unión Europea. Como el Select Committee on European Union de la Cámara de los Lores lo explicó con meridiana claridad y sinceridad años más tarde, durante la Conferencia Intergubernamental de 1991, que se culminó con la aprobación del Tratado de Maastricht, «el Gobierno británico vio la subsidiariedad como un instrumento para limitar la intervención de la UE en asuntos nacionales y mantener bajo control la futura transferencia de competencias a la $\mathrm{UE} »^{20}$.

\section{2. «Opting-out»}

A partir de este momento, el RU ha tratado de mantenerse siempre al margen de los progresos más relevantes del proceso europeo de integración, utilizando el mecanismo de mantenerse fuera — «opting-out»— de los instrumentos y regulaciones correspondientes establecidos en cada caso. El primer «opt-out» fue presentado en el mismo momento en el que se creaba la UE por el Tratado de Maastricht. Entonces, el Gobierno de John Major decidió mantenerse fuera del nuevo capítulo social del Tratado (Protocolo sobre la política social). Este «optout», sin embargo, sería cancelado por el Primer Ministro Tony Blair poco tiempo después de haber llegado al Gobierno, en mayo de 1997. Entonces, Blair firmó el Tratado de Ámsterdam en el Consejo Europeo que tuvo lugar en esa ciudad, los días 16-17 de junio de 1997, y el Tratado de Ámsterdam introduce el capítulo social en el Tratado de la Comunidad Europea (Título XI, Capítulo 1: Disposiciones sociales).

El Segundo «opt-out» fue presentado también en el momento mismo de la aprobación del Tratado de Maastricht. Entonces, el RU decidió no pasar a la tercera fase de la Unión Económica y Monetaria (UEM) (Protocolo sobre determinadas disposiciones relativas al Reino Unido de Gran Bretaña e Irlanda del Norte; actual Protocolo 15 del Tratado de Lisboa). Esto suponía mantenerse al margen

subsidiariedad, en términos generales, en el Art. 3B TCE; hoy Art. 191 del Tratado de Funcionamiento de la Unión Europea).

20 House of Lords, Eleventh Report on The Future of Europe: National Parliaments and Subsidiarity (London: House of Lords, Select Committee on European Union, 11 March 2003). 
de la nueva moneda única, que finalmente sería el euro, en 1999. La decisión de mantenerse fuera de la UEM supuso importantes consecuencias para el RU, como no participar en las instituciones de gobierno de la Eurozona (en la actualidad, la Cumbre del Euro y el Eurogroupo), en los mecanismos financieros de la UEM (el Mecanismo Europeo de Estabilidad), en los acuerdos estratégicos que rigen la UEM (el Pacto de Estabilidad y Crecimiento - Resolución del Consejo Europeo de Ámsterdam, de 17 de junio de 1997), en la formulación de la legislación que regula la UEM y el sector financiero (incluida la definición y la aplicación de las directrices generales de la política económica, la unión bancaria, etc.), excepto a través de sus representantes en el Parlamento Europeo, que no están formalmente excluidos de tomar parte en esas decisiones; $y$ en las relaciones internacionales de la UEM, en lo que se refiere a las organizaciones monetarias internacionales y a las monedas de terceos Estados. El RU, pues, carece del derecho de voto en el Consejo en lo que se refiere a esta materia. Sin embargo, el RU tiene derecho a recibir ayuda financiera de la UE en caso de caer en dificultades graves en su balanza de pagos que puedan comprometer el funcionamiento del mercado interior o la realización de la política comercial común (Art. 143 TFUE). El Bank of England está también obligado a pagar su subscripción al capital del Banco Central Europeo y a contribuir a sus costes operativos relativos a su participación en el Sistema Europeo de Bancos Centrales, en los mismos términos que todos los Estados miembros de la UE.

El tercer «opt-out» es el acuerdo de Schengen. El RU no participó en el acuerdo de Schengen concluido por cinco - Alemania, Francia, Bélgica, Países Bajos y Luxemburgo - de los entonces diez miembros de la CCEE, en esa ciudad luxemburguesa, el 14 de junio de 1985. (Los mismos Estados firmarían en 1990 la Convención de Schengen, para desarrollar el acuerdo en el marco de las nuevas circunstancias creadas por la caída del muro de Berlín). En 1997, el Tratado de Ámsterdam incorporó esta cooperación intergubernamental (que entonces había sido firmada ya por la mayoría de los Estados miembros de la UE) en el TCE, entrando en vigor el 1 de mayo de 1999. Así, para poder mantenerse fuera de esta regulación, el RU se vio obligado a presentar un nuevo «opt-out», previsto en el hoy Protocolo ( $\left.\mathrm{n}^{\circ} 19\right)$ sobre el acervo de Schengen integrado en el marco de la Unión Europea, y en el Protocolo ( $\mathrm{n}^{\mathrm{o}}$ 20) sobre la aplicación de determinados aspectos del artículo 26 del Tratado de Funcionamiento de la Unión Europea al Reino Unido y a Irlanda (al cual debe ser añadida la Declaración [n. 45] relativa al apartado 2 del artículo 5 del Protocolo sobre el acervo de Schengen integrado en el marco de la Unión Europea). Por todo ello, pues, el RU puede ejercer en sus fronteras con otros Estados miembros los controles que considere necesarios (Art. 1 del Protocolo $n^{\circ}$ 20), si bien, en correspondencia, los demás Estados miembros pueden ejercer en sus fronteras los mismos controles que deseen sobre personas procedentes del Reino Unido, o de cualquier territorio cuyas relaciones exteriores asuma el Reino Unido (Art. 3 del Protocolo ${ }^{\circ}{ }^{20}$; lo que, evidentemente, es aplicable a Gibraltar). 
Sin embargo, nos encontramos aquí con lo que podría ser denominada una previsión «opt-out / opt-in», en la medida en que esta normativa establece también que el RU puede solicitar en cualquier momento participar en algunas o en todas las disposiciones del acervo de Schengen, pero puede igualmente decidir más tarde que no desea participar en la iniciativa de que se trate, comunicándolo debidamente al Consejo (Arts. 4 y 5 del Protocolo no 19). Y, de hecho, a lo largo de estos años, el RU ha decidido incluirse en algunos aspectos relativos a la cooperación policial y judicial en materia criminal, en la lucha contra las drogas y en el Schengen Information System ${ }^{21}$.

El cuarto «opt-out» se refiere al área de libertad, seguridad y justicia. La cooperación en justicia y asuntos de interior, es decir, la cooperación policial y judicial en materia civil y penal, fue introducida por el Tratado de Maastricht como el tercer pilar de la Unión Europea. Fue entonces, en sustancia, una cooperación política intergubernamental que requería la unanimidad en el Consejo para la decisión en la práctica totalidad de sus aspectos; esto significaba que el RU podía vetar esas decisiones en función de sus propios intereses. El Tratado de Ámsterdam, sin embargo, buscando una cooperación más estrecha entre los Estados miembros en este terreno, introdujo en 1997 una aproximación conceptual diferente, que permitiese a la UE desarrollarse como «un espacio de libertad, seguridad y justicia», en el que estuviese garantizada la libre circulación de personas, si bien con la adopción de medidas comunes para el control de las fronteras exteriores, el asilo, la inmigración y la lucha contra la delincuencia (Art. B del Tratado de Ámsterdam). El Tratado de Ámsterdam, sin embargo, seguía distinguiendo entre la cooperación policial y judicial en materia penal, materia propiamente intergubernamental, que se regula en el TUE (Título VI), y las otras políticas relacionadas con la libre circulación de personas, visados, asilo, inmigración, que se pasan al pilar comunitario, al TCE (Tercera Parte, Título IV). En desarrollo de las previsiones del Tratado de Ámsterdam, el Consejo Europeo de Tampere (1516 de octubre de 1999) transfirió de manera efectiva al pilar comunitario buena parte del contenido sustantivo del tercer pilar; sin embargo, la decisión por unanimidad fue mantenida para estas materias, lo que seguía asegurando al RU su derecho de veto en el Consejo. Sería el Tratado de Lisboa (2007), que crea la Unión Europea en su actual forma, el que cambiase el panorama. Así, el Tratado de Lisboa comunitariza de manera definitiva todas estas materias - cooperación policial, cooperación judicial en materia civil y penal, controles fronterizos, asilo e inmigración-y las regula de manera conjunta en un nuevo Título (Título V: Espacio de libertad, seguridad y justicia, de la Tercera Parte del TFUE), estableciendo además que la mayoría de los aspectos referidos a estas materias se regulen mediante el procedimiento legislativo ordinario; es decir requiriendo sólo la

21 House of Lords, The UK's opt-in Protocol: implications of the Government's approach (London: House of Lords, European Union Committee, 9th Report of Session 2014-15, 24 March 2015). 
mayoría cualificada en el Consejo. Esto suponía que el RU perdía el derecho de veto en el Consejo sobre estas materias, lo que, una vez más, le llevó a exigir un nuevo «opt-out». En este caso, el «opt-out» fue regulado por el Protocolo ( $\left.n^{\circ} 21\right)$ sobre la posición del Reino Unido y de Irlanda respecto del espacio de libertad, seguridad y justicia; la Declaración [65] del Reino Unido de Gran Bretaña e Irlanda del Norte relativa al artículo 75 del Tratado de Funcionamiento de la Unión Europea (referido a la lucha contra el terrorismo); y la Declaración [56] de Irlanda relativa al artículo 3 del Protocolo sobre la posición del Reino Unido y de Irlanda respecto del espacio de libertad, seguridad y justicia.

Este «opt-out», pues, significa que el RU no participa en la adopción por el Consejo de medidas referidas a las materias del Título V de la Tercera Parte del TFUE, y que, por tanto, esas medidas no le vinculan. Sin embargo, como ocurre en el caso del «opt-out» sobre el acuerdo de Schengen, el RU puede decidir en cualquier momento participar en la adopción de decisiones sobre cualquier aspecto de estas materias y, por consiguiente, considerarse vinculado por las mismas; algo que, en realidad, ha ocurrido ya en 67 ocasiones en el período 2011 $2014^{22}$. En este sentido, se trata aquí, pues, más de una medida «opt-out / opt-in», que de una medida «opt-out» solamente.

El quinto «opt-out» se refiere a la Carta de los Derechos Fundamentales de la Unión Europea. Este «opt-out» fue presentado en el momento de la fima del Tratado de Lisboa y fue suscrito también por Polonia (Protocolo $\mathrm{N}^{\circ} 30$ sobre la aplicación de la Carta de los Derechos Fundamentales de la Unión Europea a Polonia y al Reino Unido). Este «opt-out» pretende que las disposiciones de la Carta sólo sean aplicables en Polonia o en el Reino Unido en la medida en que los derechos y principios que contienen estén reconocidos en la legislación o prácticas de Polonia o del Reino Unido (Art. 2 del Protocolo $N^{\circ} 30$ ), y que, en esta línea, ni el Tribunal de Justicia de la Unión Europea ni ningún otro órgano jurisdiccional de Polonia o del Reino Unido tendrán competencia para apreciar si las disposiciones legales o reglamentarias de Polonia o del Reino Unido son compatibles con los derechos y principios establecidos en la Carta (Art. 1 del Protocolo No 30).

Sin embargo, el verdadero significado de este Protocolo y su aplicación práctica han sido cuestionados en la doctrina científica ${ }^{23}$ y por el propio TJUE. El argumento es que las previsiones de los artículos 1 y 2 del Protocolo $\mathrm{N}^{\circ} 30$ no sólo están en contradicción con lo establecido en su mismo preámbulo, sino que, en todo caso, son una mera reiteración de lo ya establecido en el Art. 6 del TFUE y en la propia Carta, en su Art. 51 y en su Preámbulo. Se trata, pues, de una previsión inútil. En este sentido, como dice el Tribunal, «el Protocolo nº 30 no cuestiona la vigencia de la Carta para el Reino Unido y Polonia», dado que, según el

22 House of Lords, The UK's opt-in, cit.

23 Véase, por todos, O’Neill, A., QC, «Is the UK's 'opt-out' from the EU Charter of Fundamental Rights worth the paper it is written on?», EUtopia Law, September 15, 2011. 
sexto considerando del preámbulo de dicho Protocolo, «la Carta reafirma los derechos, libertades y principios reconocidos en la Unión y hace que dichos derechos sean más visibles, pero no crea nuevos derechos ni principios». Algo que, en realidad, ya estaba previsto en el apartado quinto del Preámbulo de la Carta ( «La presente Carta reafirma, ... , los derechos que emanan, en particular, de las tradiciones constitucionales y las obligaciones internacionales comunes a los Estados miembros») y en su Art. 51, el cual, en su párrafo $1^{\circ}$, obliga además a los Estados a su cumplimiento, en el marco de la aplicación del Derecho de la Unión. En esta línea, añade el Tribunal, «el artículo 6 TUE dispone que la Carta ha de ser aplicada e interpretada por los órganos jurisdiccionales de la República de Polonia y del Reino Unido de estricta conformidad con las explicaciones a que se hace referencia en ese artículo». Así, concluye el TJUE, «el artículo 1, apartado 1, del Protocolo ( ${ }^{\circ} 30$ ) hace explícito el artículo 51 de la Carta, relativo al ámbito de aplicación de esta última, y no tiene por objeto eximir a la República de Polonia y al Reino Unido de la obligación de respetar las disposiciones de la Carta, ni impedir que un órgano jurisdiccional de uno de estos Estados miembros vele por que se respeten tales disposiciones $»^{24}$. El Protocolo ( $\mathrm{n}^{\mathrm{o}} 30$ ), pues, tal y como ha sido redactado y más allá de lo que fuesen las intenciones iniciales del RU y de Polonia, no excluye verdaderamente a estos Estados de la aplicación de la Carta, sino que se limita a reafirmar las previsiones de ésta y, en consecuencia, su plena vigencia en los términos de los Tratados (vid. Art. 6 del TUE).

Pero, el RU no sólo ha presentado sus «opt-outs» a las previsiones mencionadas de los Tratados de la UE, sino que ha decidido mantenerse también al margen de otros acuerdos substantivos referidos al gobierno de la Unión. Quizá el caso más relevante $-\mathrm{y}$ reciente — de ellos lo sea la decisión de mantenerse al margen del Tratado de Estabilidad, Coordinación y Gobernanza en la Unión Económica y Monetaria (TECG), firmado en Bruselas por 25 de los entonces 27 Estados miembros de la UE (todos, excepto el RU y la República Checa), el 2 de marzo de 2012. Inicialmente y en apariencia, esta decisión del RU es coherente con su «opt-out» con respecto a la UEM; sin embargo, este Tratado había sido inicialmente concebido como parte de un plan más amplio de reforma de la UE promovido por la Canciller alemana Angela Merkel y el entonces Presidente de Francia, Nicolas Sarkozy. El objetivo era realizar una reforma de los tratados de la Unión para mejorar su funcionamiento en varios aspectos, principalmente la gobernanza económica, en un momento de grave crisis económica y financiera, que afectaba con mayor dureza a varios Estados miembros de la eurozona. Fue precisamente la oposición del Primer Ministro británico David Cameron (y también la del Presidente checo Václav Klaus) lo que forzó, primero, al cambio de planes y a limitar el objetivo de la reforma y, segundo, a concluir el Tratado fuera del marco del

24 Tribunal de Justicia de la Unión Europea, Sentencia del Tribunal de Justicia (Gran Sala), de 21 de diciembre de 2011. Asuntos acumulados C-411/10 y C-493/10, para. 116-122. 
ordenamiento jurídico de la UE, dado que el veto del RU y de la República Checa impedía que se pudiese producir una reforma ordinaria de los Tratados. El TECG, pues, limita sus objetivos a «reforzar el pilar económico de la unión económica y monetaria mediante la adopción de un conjunto de normas destinadas a promover la disciplina presupuestaria a través de un pacto presupuestario, a reforzar la coordinación de sus políticas económicas y a mejorar la gobernanza de la zona del euro», como establece su Art. 1, y vincula sólo a los Estados signatarios, tanto a los que son parte de la eurozona, como a los que aún no lo $\operatorname{son}^{25}$.

Es interesante destacar aquí que el TECG, aunque concluido al margen del ordenamiento jurídico de la UE, establece instituciones de gobierno de la eurozona que son, por ello, propias de la UE. Tal es el caso de la Cumbre del Euro (que reúne a los Jefes de Estado o de Gobierno de los Estados miembros de la eurozona y al Presidente de la Comisión ${ }^{26}$ y del Presidente de la Cumbre del Euro (Art. 12 TECG) ${ }^{27}$. Ello, unido a la existencia previa del Eurogrupo (creado por el Art. 137 del TFUE y regulado por el Protocolo $N^{\circ} 14$ sobre el Eurogrupo), supone la existencia de una estructura institucional de gobierno de la UE paralela a la ordinaria, si bien referida específicamente a la eurozona, lo que hace que, en buena parte de los casos, las decisiones que se van a adoptar en el Consejo Europeo, o en el Consejo — en su formación de Economía y Finanzas-, hayan sido ya previamente acordadas o, en todo caso, vayan a estar muy condicionadas por las decisiones adoptadas previamente por esta estructura institucional de la eurozona. Y esto — como se verá más adelante con detalle - ha sido una de las quejas permanentes del RU, dado que siempre se ha sentido desplazado e ignorado en esas decisiones, al no formar parte de las instituciones de gobierno de la eurozona.

\section{EL ÚLTIMO INTENTO DE ACOMODO: CAMERON Y EL CONSEJO EUROPEO DE FEBRERO DE 2016}

Si se analizan con detalle las condiciones que se derivan de los «opt-outs» conseguidos por el RU, no puede menos que concluirse que la situación del RU en

25 Croacia, tras su ingreso en la UE, el 1 de julio de 2013, no ha firmado aún el TECG. En el caso de la República Checa, el Gobierno decidió firmar el TECG en su reunión del 24 de marzo de 2014, sin embargo, no ha llegado a concluir el proceso de ratificación.

26 La Cumbre del Euro, en realidad, venía reuniéndose ya en la práctica, de manera irregular, desde 2008, por lo que el TECG lo que viene a hace es formalizar jurídicamente esta institución.

27 El Art. 12 del TECG establece que el Presidente de la Cumbre del Euro será elegido al mismo tiempo que se elija el Presidente del Consejo Europeo y para un mandato de igual duración; además, la Cumbre del Euro, en su reunión del 26 de octubre de 2011, acordó que el Presidente de la Cumbre del Euro fuese la misma persona que el Presidente del Consejo Europeo (Secretaría General del Consejo, Normas para la organización de los trabajos de las Cumbres del Euro, Bruselas, Marzo de 2003, p. 21). Con ello, se conseguía evitar una duplicación institucional, si bien a costa de producir una confusión institucional. De hecho, en la actualidad, se produce la paradoja de que la presidencia de la Cumbre del Euro la ocupa una persona —Donald Tusk, Presidente también del Consejo Europeo- que es ciudadano de un Estado que no es miembro de la eurozona. 
el seno de la UE ha sido hasta ahora verdaderamente privilegiada: se beneficia de las ventajas económicas que se derivan de su pertenencia al mercado interior y, desde luego, de su posición en el seno de las instituciones de gobierno de la UE (excepto las de la eurozona), al mismo tiempo que mantiene a salvo los aspectos clave de su soberanía en el terreno monetario y financiero, y en el control de sus fronteras; además, claro es, de recibir una importante compensación en su contribución a los presupuestos de la UE a través del denominado «cheque británico». Su pertenencia al mercado interior, sin embargo, le obliga a aceptar y respetar las cuatro libertades básicas que son los cuatro pilares de éste: la libre circulación de personas, mercancías, servicios y capitales.

¿Qué es, por tanto, lo que ha llevado al RU a mantener desde el inicio esa posición incómoda, desconfiada y restrictiva en el seno de la UE? En realidad, son varias y complejas las razones. Entre ellas, no se pueden ignorar $a$ ) los aspectos psicológicos e históricos: el tradicional aislacionismo británico, derivado de su condición geográfica de isla, y las atormentadas relaciones históricas con las otras potencias del continente, España, Francia, Alemania; $b$ ) el diferente concepto que el RU tuvo desde el inicio sobre el proceso de integración europeo, al que siempre concibió sólo como un área de libre cambio, al contrario de lo que habían previsto los padres fundadores; $y$, en la actualidad, principalmente $c$ ) los argumentos de tipo utilitario: la necesidad de mantenerse al margen de la turbulenta situación económica y financiera de la Europa de los años 2008-2015 y, sobre todo, el problema de la inmigración masiva de ciudadanos del Este de Europa - principalmente Polonia-, añadida a la crisis de los refugiados provenientes del Oriente Medio y de África. En medio de todo ello y, en buena medida, provocado por todo ello, la inestable situación política interna: la debilidad del primer Gobierno Cameron, que gobernaba en coalición con los liberales desde las elecciones de 2010, y el ascenso vertiginoso del nacionalismo populista y eurófobo, cuyo voto fue capitalizado por el UKIP en las elecciones al Parlamento Europeo de mayo de 2014 y que amenazaba con dar su salto al Parlamento británico y reducir aún más el voto del partido conservador.

Es en este contexto como el Primer Ministro Cameron decidió convocar un referéndum sobre la permanencia del RU en la UE, en la idea de ser él quien asumiese el liderazgo de todo el proceso, forzando, primero, una renegociación de los términos de la adhesión del RU a la UE y, después, la convocatoria de un referéndum sobre esos nuevos términos de la adhesión a la UE, en el que él lideraría la campaña del sí. En realidad, la visión de la UE que tenía Cameron seguía siendo la misma que, de manera prácticamente inalterada, habían tenido todos los Primeros Ministros británicos — laboristas y conservadores - desde que Harold Macmillan presentase la primera solicitud de adhesión a las CCEE en 1961. Así, el 23 de enero de 2013, Cameron pronunció un discurso en la sede de Bloomberg, en Londres, en el que no solo anunció que iba a convocar un referéndum sobre la permanencia del RU en la UE, sino que dejó claramente de manifiesto cuál era su visión de la UE y, en realidad, la mentalidad con la que el RU se había 
acercado siempre a la UE. Las palabras de Cameron son muy reveladoras: «Tenemos el carácter de una nación insular, independiente, franca y apasionada en defensa de nuestra soberanía. No podemos cambiar esta sensibilidad británica de la misma manera que tampoco podemos drenar el Canal de la Mancha. Y debido a esta sensibilidad, venimos a la Unión Europea con un ánimo más práctico que emocional. Para nosotros, la Unión Europea es un medio para alcanzar un fin -la prosperidad, la estabilidad, asegurar la libertad y la democracia dentro de Europa y más allá de sus fronteras— no un fin en sí misma» ${ }^{28}$.

Para Cameron — como también para los demás Primeros Ministros que le precedieron en el cargo_-, la UE debería ser simplemente un mercado y, por lo tanto, todo avance en la consecución de «una unión cada vez más estrecha entre los pueblos de Europa», tanto en términos económicos como, desde luego, en términos políticos, suponía un inconveniente para la realización del mercado único y, por lo tanto, debía ser evitada.

Por todo ello, pues, David Cameron anunció que estaba dispuesto a convocar un referéndum para afrontar esta cuestión. Sin embargo, para convocarlo, debía ganar las siguientes elecciones parlamentarias, que él mismo convocó para el 7 de mayo de 2015. De hecho, el programa electoral del partido conservador incluyó entre sus promesas la renegociación de los términos de la pertenencia del RU a la UE, y, sobre ello, la convocatoria de un referéndum sobre la permanencia del RU en la UE, antes del final de $2017^{29}$.

Tras haber ganado las elecciones con una amplia mayoría, y en cumplimiento de sus promesas, Cameron dirigió una carta al Presidente del Consejo Europeo, Donald Tusk, el 10 de noviembre de 2015, en la que señaló cuatro áreas en las que exigía reformas a efectos de poder mantener al RU en la UE. En términos resumidos estas áreas y las principales exigencias correspondientes fueron las siguientes: a) «Gobernanza Económica»: Establecer mecanismos de garantía para asegurar la integridad del mercado interior y la posición de los Estados que no pertenecen al Euro. b) «Competitividad»: Aumentar la productividad y la competitividad de las empresas mediante la reducción de la carga reguladora; promocionar el mercado digital y los acuerdos comerciales con USA, China, Japón y la ASEAN. c) «Soberanía»: Excluir al RU del proceso de creación de «una unión cada vez más estrecha entre los pueblos de Europa» ( «ever closer union»), previsto en el preámbulo y en el Art. 1 del TUE; fortalecer el papel de los Parlamentos nacionales en el control de la subsidiariedad; preservar el respeto de la seguridad nacional de los Estados en el ámbito de justicia y asuntos de interior. d) «Inmigración»: Exigir que los inmigrantes de la

28 Traducción propia del original inglés: CAmeron, D., «EU speech at Bloomberg» (The Prime Minister's Office, 10 Downing Street, and The Rt Hon David Cameron MP. Delivered on: 23 January 2013); en: https://www.gov.uk/government/speeches/eu-speech-at-bloomberg.

29 Conservative Party, The Conservative Party Manifesto 2015: Strong Leadership, a Clear Economic Plan, a Brighter, More Secure Future (London: The Conservative Party, 2015). 
UE en el RU contribuyan un mínimo de 4 años para poder acceder a las prestaciones sociales y asistenciales ${ }^{30}$.

En realidad, en términos generales, las exigencias de Cameron tenían más de operación de imagen, dirigida hacia el electorado británico, que de pretensión sustantiva de reforma de la UE, dado que muchas de ellas pretendían cosas que estaban —están - ya en vigor en el ámbito de la $U^{31}$. Sólo la cuestión de la soberanía y la cuestión de la inmigración planteaban verdaderos problemas. La cuestión de la soberanía, porque pretendía redefinir el concepto sustantivo de la UE; y la inmigración porque las pretensiones del Gobierno británico no se dirigían tanto a prevenir los problemas planteados por la llegada masiva de refugiados y la inmigración ilegal provenientes del Oriente Medio y de África, sino más bien a prevenir la inmigración masiva de trabajadores del Este de Europa, lo que afectaba directamente al corazón mismo de la libertad de circulación. Y, desde luego, estas exigencias encontraron pronto la respuesta contraria de los Estados del Centro y del Este de Europa ${ }^{32}$.

Tras difíciles negociaciones ${ }^{33}$ y un primer intento frustrado ${ }^{34}$, los Jefes de Estado o de Gobierno de la UE llegaron a un acuerdo en su reunión del 18-19 de febrero de 2016. El acuerdo fue difícil, como difícil fue también articularlo jurídicamente, dado el carácter diverso de las exigencias planteadas y, sobre todo, por el hecho de que las partes negociadoras eran dos partes de la propia UE: el RU, por un lado, y los demás Estados miembros de la UE, por otro. En este sentido, el acuerdo no era una norma jurídica de la UE — no era el Consejo Europeo, en términos propios, quien adoptaba la decisión-, pero tampoco era un tratado internacional ordinario concluido como tal, con todas las formalidades al uso; era, en realidad, un acuerdo político, una mera declaración de intenciones sobre posibles reformas jurídicas a adoptar en el futuro, en el supuesto de que se produjese el hecho determinante que abriría ese proceso de reforma: la decisión final del RU de permanecer en la $\mathrm{UE}^{35}$. De hecho, el acuerdo se estructuró en dos grandes bloques:

30 Traducción propia del original en inglés: Cameron, David, PM letter to President of the European Council Donald Tusk, London, 10 November 2015; en: https:/www.gov.uk/government/uploads/system/ uploads/attachment_data/file/475679/Donald_Tusk_letter.pdf

31 Se volvía a producir así un fenómeno similar al que se había producido ya en el caso de Irlanda, tras el fracasado referéndum del 12 de junio de 2008 sobre el Tratado de Lisboa, y las concesiones hechas al Gobierno irlandés por el Consejo Europeo, en sus reuniones de diciembre de 2008 y de junio de 2009. (Véase el Protocolo sobre las preocupaciones del pueblo irlandés con respecto al Tratado de Lisboa, firmado y anexado al Tratado de Lisboa el 13 de junio de 2012).

32 Véase el Joint Statement of the Visegrad Group Countries Regarding European Council Issues (Brussels, December 17, 2015), en: http:/www.visegradgroup.eu/calendar/2015/joint-statement-of-the-151221-1.

33 Véase Miller, V., EU reform negotiations: What's going on? (London: House of Commons, Briefing Paper $\mathrm{n}^{\circ} 7311,5$ January 2016), y Miller, V., UK's EU reform negotiations: The Tusk package (London: House of Commons, Briefing Paper $n^{\circ} 7497,9$ February 2016).

34 Consejo Europeo (2015), Reunión del Consejo Europeo 17 y 18 de diciembre de 2015 - Conclusiones (Bruselas, 18 de diciembre de 2015, EUCO 28/15 CO EUR 13, CONCL 5).

35 La Decisión, sin embargo, se autodefinía como un documento jurídico: «la Decisión es jurídicamente vinculante y puede modificarse o derogarse sólo de común acuerdo por los jefes de Estado o de Gobierno 
por un lado, un acuerdo político marco entre los jefes de Estado o de Gobierno (en adelante JEoG) de los demás Estados miembros con el RU («Decisión de los jefes de Estado o de Gobierno, reunidos en el seno del Consejo Europeo, relativa a un nuevo régimen para el Reino Unido en la Unión Europea»), que figura en el Anexo 1 de las Conclusiones del Consejo Europeo. Esta Decisión de los JEoG abordaba cada uno de los cuatro grupos de exigencias que habían sido planteados en la carta de David Cameron y, por tanto, contenía la sustancia del acuerdo entre las dos partes. Y, por otro lado, se formuló una serie de seis declaraciones sobre diferentes materias, que son, en realidad, meras declaraciones de intención de abordar las reformas que se anuncian en cada una de ellas: una Declaración del Consejo Europeo sobre competitividad (Anexo 3); una Declaración del Consejo sobre la unión bancaria y la integración de la zona del euro (Anexo 2); y cuatro declaraciones de la Comisión Europea, sobre la subsidiariedad y la reducción de las cargas (Anexo 4), sobre las prestaciones por hijos de los trabajadores inmigrantes (Anexo 5), sobre la restricción de la libertad de circulación de trabajadores en casos excepcionales (Anexo 6), y sobre el abuso del derecho de libre circulación de personas (Anexo 7) ${ }^{36}$.

Dado que el acuerdo carece ya de validez, por cuanto su vigencia quedó condicionada a la aprobación del referéndum de permanencia del RU en la UE, cosa que finalmente no se produjo ${ }^{37}$, no merece la pena entrar en el detalle del mismo $^{38}$, Por otra parte —como hemos visto en páginas anteriores—, buena

de los Estados miembros de la Unión Europea». A lo que se añadía: «esta Decisión otorga garantía jurídica de que se han abordado las cuestiones que preocupan al Reino Unido reflejadas en la carta de 10 de noviembre de 2015» (Consejo Europeo, Reunión del Consejo Europeo, 18 y 19 de febrero de 2016 - Conclusiones, Bruselas, 19 de febrero de 2016, EUCO 1/16, CO EUR 1, CONCL 1, p 2). El Servicio Jurídico del Consejo hizo un detallado dictamen previo sobre la Decisión, calificándola de «instrument of international law, concluded in a simplified form», cuyo valor jurídico se basa en la voluntad de las partes de darle valor vinculante, y no en la forma de manifestarse esta voluntad, de acuerdo con el Art. 11 de la Convención de Viena sobre el Derecho de los Tratados (European Council, Opinion of the Legal Counsel on the Draft Decision of the Heads of State or Government, meeting within the European Council, concerning a new settlement for the United Kingdom within the European Union (doc. EUCO 4/16): Form, legal nature, legal effects and conformity with the EU Treaties, Brussels, 8 February 2016 (OR. en) EUCO 15/16, LIMITE JUR64). Y en la misma línea se manifestó el propio Gobierno Británico, reafirmando el valor jurídico del acuerdo conseguido (HM Government, The best of both worlds: The United Kingdom's special status in a reformed European Union, London: Her Majesty's Stationery Office, 2016, pp. 33-36). Sobre la controvertida naturaleza jurídica de esta Decisión de los JEoG véase un detallado análisis en: LANG, A (et al.), EU Referendum: summary and analysis of the new Settlement for the UK in the EU (House of Commons, Briefing Paper n 7524, 26 May 2016); y, en España: MARTín PÉREZ dE NANCLAREs, J., «La Unión Europea ante el desafío del Brexit: De la Decisión de los Jefes de Estado o Gobierno a la activación del procedimiento de retirada», en Actualidad Jurídica Uría Menéndez, no 43, 2016, pp. 7-24.

36 Consejo Europeo, Reunión del Consejo Europeo, 18 y 19 de febrero de 2016, cit. La decisión del Consejo Europeo recuerda mucho a la adoptada en 1975, en la primera renegociación con el RU — que analizamos en páginas anteriores_- en la medida que, entonces como aquí, había sólo un compromiso de futuras reformas, que, en aquel caso, nunca llegaron a realizarse en su mayor parte.

37 «La presente Decisión — decía el acuerdo— surtirá efecto el mismo día en que el Gobierno del Reino Unido informe al secretario general del Consejo de que el Reino Unido ha decidido seguir siendo miembro de la Unión Europea» (Consejo Europeo, Reunión del Consejo Europeo, 18 y 19 de febrero de 2016, cit., p. 2).

38 Véase un detallado análisis del complejo contenido del acuerdo UE-RU en: BAR CENDón, A., «The UK, the EU and 'Brexit': 1972-2017», en Solanes, A.; Górriz, E. (eds.), Legal Challenges of the XXI Century, 
parte de las demandas de Cameron se referían a normas y decisiones ya adoptadas y vigentes en el momento de enviar su carta (así, por ejemplo, en los ámbitos de la gobernanza económica y de la eurozona, de la competitividad, de la subsidiariedad, o del área de libertad, seguridad y justicia). Baste mencionar aquí, pues, sólo aquellos aspectos en los que los JEoG hicieron concesiones verdaderamente sustantivas al RU, que - en nuestra opinión-, ponían en cuestión la verdadera sustancia de la UE y que, por tanto, deberían servir como ejemplo de lo que la UE no debería conceder nunca más, bajo grave riesgo de negarse a sí misma. Estos aspectos son: la definición sustantiva de la UE como un proceso progresivo de una unión cada vez más estrecha entre los pueblos de Europa, y la libertad de circulación de los trabajadores, así como los derechos y beneficios sociales de los inmigrantes.

Desde el punto de vista de este trabajo, es el primero de esos aspectos el que merece mayor atención. Así, efectivamente, entre las controvertidas concesiones hechas al RU, es la referida al proceso progresivo de integración de la UE —que Cameron incluía bajo el epígrafe de «soberanía»—, la que tiene mayor relevancia y hubiese tenido una mayor repercusión en la articulación y devenir futuro de la UE. En esta cuestión, los JEoG decidieron ignorar el valor definidor de la sustancia de la UE que supone la afirmación de que la UE es un «proceso de creación de una unión cada vez más estrecha entre los pueblos de Europa» (preámbulo del TUE) y de que, en este sentido, la actual UE es sólo «una nueva etapa» en ese proceso (Art 1 TUE). Definición que entronca plenamente con la filosofía que inspiró a los padres creadores de las Comunidades Europeas, para quienes aquéllas eran sólo un escalón en el camino de la creación de los «Estados Unidos de Europa», en los términos de Churchill. Así, los JEoG decidieron entender que «las referencias a una unión cada vez más estrecha entre los pueblos son compatibles con las diferentes vías de integración a disposición de los Estados miembros y no obligan a todos los Estados miembros a buscar una meta común $»^{39}$. En este sentido, los JEoG afirmaron que el $\mathrm{RU}$ «no [está] comprometido a una mayor integración política en el seno de la Unión Europea» y, además, decidieron que esta afirmación debería ser incorporada a los Tratados en el momento de su próxima revisión, «a fin de aclarar que las referencias a una unión cada vez más estrecha no se aplican al Reino Unido» ${ }^{40}$.

De esta manera, finalmente, los temores manifestados por el Presidente De Gaulle en los años sesenta y setenta del siglo pasado se hacían realidad: el RU,

Tirant lo Blanch, Valencia, 2017, pp. 79-127; y MANGAS, A., «La retirada del Reino Unido de la Unión Europea», Foro, Nueva época, vol. 19, n 1, 2016, pp. 29-63.

39 Una afirmación similar, en realidad, ya la había hecho el propio Consejo Europeo, en su reunión de 26-27 de junio de 2014 (Consejo Europeo, Consejo Europeo 26 y 27 de junio de 2014 - Conclusiones, Bruselas, 27 de junio de 2014, EUCO 79/14, CO EUR 4, CONCL 2, p. 11).

40 Consejo Europeo, Reunión del Consejo Europeo, 18 y 19 de febrero de 2016, cit., pp. 15-17. 
lejos de adaptarse a la filosofía, valores y principios de la UE, forzaba a ésta, desde dentro, a adaptarse a los suyos.

Satisfecho como quedó con el acuerdo conseguido, Cameron decidió aprovechar el momento y convocó inmediatamente el referéndum, en vez de esperar hasta 2017, como había planeado inicialmente, cuando propuso la European Union Referendum Bill 2015-16. Así, el 22 de febrero de 2016, anunció en el Parlamento que iba a iniciar inmediatamente el proceso previsto en la European Union Referendum Act 2015 (c. 36) para convocar un referéndum sobre la permanencia del RU en la UE el 23 de junio de 2016.

La satisfacción de Cameron era tan grande que el informe que el Gobierno tenía que publicar sobre la materia, en aplicación de la sección 6 de la European Union Referendum Act 2015, explicando el resultado de las negociaciones con la UE, fue titulado, de manera muy significativa: "The best of both worlds: The United Kingdom's special status in a reformed European Union» ${ }^{41}$. Es verdad, sin embargo, que para proporcionar una perspectiva completa de la situación, el Gobierno británico publicó también otros dos informes titulados: "Alternatives to membership: Possible models for the United Kingdom outside the European Union» $\mathrm{y}$ "The process for withdrawing from the European Union» ${ }^{42}$.

La cuestión que cabe plantearse ahora aquí es ¿qué ocurriría si el RU decidiese volver sobre sus propios pasos y quisiese permanecer en la UE? ¿volvería este acuerdo — cancelado por el resultado negativo del referéndum del 23 de junio de 2016 — a tener validez? La primera respuesta que habría que dar a estas preguntas es que, tal y como se están produciendo las cosas y a juzgar por el posicionamiento político de los dos grandes partidos británicos — favorable al respeto de los resultados del referéndum - no parece muy probable que el RU quiera volverse atrás en su decisión de abandonar la UE. En segundo lugar, desde un punto de vista estrictamente jurídico, no creo que el acuerdo pueda ser puesto en vigencia de nuevo, dado que estaba sometido a una cláusula resolutoria —el sí en el referéndum — que nunca llegó a cumplirse; en este sentido, pues, el acuerdo ha quedado cancelado. En esta línea, entiendo igualmente que, si el RU decidiese permanecer en la UE antes de que concluyese el plazo de dos años previsto en el Art. 50 TUE para la conclusión de un acuerdo de separación, debería hacerlo en las condiciones ordinarias acordadas en su Tratado de Adhesión de 1972. En tercer lugar, desde un punto de vista puramente político, en cambio, entiendo que nada se opondría a que los demás JEoG de la UE decidiesen mantener o, más bien, volver a adoptar el acuerdo concluido, u otro de iguales términos, si se diesen las circunstancias.

41 HM Government, The best of both worlds: The United Kingdom's special status in a reformed European Union (London: Her Majesty's Stationery Office, 2016).

42 HM Government, Alternatives to membership: Possible models for the United Kingdom outside the European Union (London: Her Majesty's Stationery Office, 2016); y HM Government, The process for withdrawing from the European Union (London: Her Majesty’s Stationery Office, 2016). 


\section{LA RUPTURA DE LA RELACIÓN: EL REFERÉNDUM DE JUNIO DE 2016}

El referéndum sobre la permanencia del RU en la UE tuvo lugar el 23 de junio de 2016 y el peor resultado imaginable se convirtió en una realidad: el RU decidió abandonar la UE, si bien por un reducido margen de votos (el 3,8\%).

La cuestión planteada a los votantes británicos fue: «Should the United Kingdom remain a member of the European Union or leave the European Union?» (¿Debería el Reino Unido permanecer como miembro de la Unión Europea o abandonar la Unión Europea») ${ }^{43}$. Y el resultado nacional fue 17,4 millones de votos (el 51,9\%) a favor de abandonar la UE (en adelante «leave»), y 16,1 millones de votos (el $48.1 \%$ ) a favor de permanecer en la UE (en adelante «remain»). La participación fue muy elevada (el $72,2 \%$ ), lo que dio al proceso una alta dosis de legitimación democrática. Una cuestión diferente, digna de ser considerada aquí, es si una decisión de tal transcendencia política y constitucional, y graves consecuencias de todo tipo - políticas, económicas, sociales - puede ser adoptada por un margen tan reducido de votos que supera en muy poco la mitad del electorado. Y en la misma línea inciden los análisis sociológicos, que resaltan las claras líneas divisorias que se produjeron en la distribución territorial y demográfica del voto.

Dejando a un lado las consideraciones puramente sociológicas ${ }^{44}$, desde un punto de vista jurídico-constitucional, debe resaltarse que ni la European Union Referendum Act 2015, que reguló de manera específica este proceso, ni la más general Political Parties, Elections and Referendums Act 2000, en lo que pudiese ser aplicable, establecen disposición alguna que exigiese un quorum de participación, o un número o porcentaje determinado de síes para que la decisión pudiese ser considerada como adoptada. En este sentido, debe resaltarse que las recomendaciones de la Comisión de Venecia en esta materia no sólo recomiendan no establecer un quorum de participación determindo («because it assimilates voters who abstain to those who vote no»), sino que tampoco recomiendan exigir un porcentaje determinado de votos favorables — quorum de aprobación — para aprobar una decisión (dado que «the majority will feel that they have been deprived of victory without an adequate reason» $)^{45}$. Es interesante destacar aquí, sin embargo, que en julio de 2016, se presentó ante el Parlamento británico —Petitions Committee- una

43 European Union Referendum Act 2015 (c. 36), clause 1(4).

44 Véase, en este ámbito, el interesante y detallado análisis realizado por Ashcroft, M. A. P., «How the United Kingdom voted on Thursday... and why» (Lord Ashcroft Polls, 24 June 2016), en: http://lordashcroftpolls.com/2016/06/how-the-united-kingdom-voted-and-why.

45 Venice Commission, Code of Good Practice on Referendums (Adopted by the Council for Democratic Elections at its 19th meeting and the Venice Commission at its 70th plenary session, Venice, 16-17 March 2007) (Council of Europe, Study N $\mathrm{N}^{\mathrm{3}} 371 / 2006$, CDL-AD(2007)008, Strasbourg, 19 March 2007), pp. 14, 22; Venice Commission, Guidelines for Constitutional Referendums at National Level (Adopted by the Venice Commission at its 47th Plenary Meeting, Venice, 6-7 July 2001) (Council of Europe, CDL-INF (2001)10, Strasbourg, 11 July 2001), p. 7. 
petición firmada por más de 4 millones de firmas (en el RU son suficientes 100 mil firmas para poner una moción a debate ante el Parlamento), cuya recogida se había iniciado ya en mayo de 2016, antes de la celebración del referéndum, en la cual se pedía que, si el resultado del referéndum suponía que el voto mayoritario a favor de la permanencia, o a favor de la salida de la UE, fuese inferior al 60\% de los votos, y que si la participación fuese inferior al $75 \%$ del censo, se debía convocar un segundo referéndum sobre la cuestión. La petición fue debatida por el Parlamento el 5 de septiembre de 2016, pero no llegó a ser aprobada ${ }^{46}$. No cabe duda alguna, pues, sobre la legalidad y la legitimidad del resultado del referéndum del Brexit.

En todo caso, el resultado fue una gran conmoción que hizo temblar tanto las paredes del edificio de la UE, como las del Gobierno del propio RU. En realidad, se trataba de algo previsible. Las encuestas de opinión, aun con ciertas oscilaciones, daban en las semanas previas al referéndum una ventaja a la opción «leave» que iba de uno a cuatro puntos ${ }^{47}$. Por otra parte, a diferencia de lo que había ocurrido en el referéndum de 1975 , la campaña a favour de «leave» fue mucho más contundente y agresiva $-\mathrm{y}$ también mendaz-, y sus argumentos insistieron más en los aspectos positivos y esperanzadores de un nuevo RU sin las ataduras de la UE, mientras que la campaña del «remain» fue más ligera e insistió más en el miedo, en las consecuencias negativas que la salida de la UE podría llevar consigo. Por otra parte, tanto la opción «leave», como la opción «remain» fueron más transversales que en 1975 y estuvieron similarmente distribuidas entre todos los grupos y en el seno del propio Gobierno, que se dividió en dos partes prácticamente iguales.

El escenario, pues, fue bastante distinto al que se produjo en 1975. En 2016, el campo del «remain», fue mucho más débil y reducido; el Gobierno se encontraba dividido prácticamente por la mitad y el partido conservador se dividió también en dos campos prácticamente iguales; el partido laborista, si bien se dividió también, como en 1975, careció en cambio de un liderzago fuerte a favor del «remain», que sí lo tuvo en 1975; no hubo una organización verdaderamente fuerte a favor del «remain», como sí lo fue el partido laborista - a pesar de su división interna- en 1975. Y, en fin, el partido conservador de Cameron y el partido laborista de Corbyn no cooperaron en la campaña a favor del «remain», como sí lo hicieron, en cambio, en 1975. Y, desde luego, a diferencia de lo ocurrido en 1975, en 2016 buena parte de la prensa — principalmente los tabloides, de enorme difusión, como The Sun, The Express, The Daily Mail, The Telegraph-, fueron muy radicales en su campaña a favor de abandonar la UE. Sólo la prensa

46 UK Government and Parliament, Petition. EU Referendum Rules triggering a 2nd EU Referendum (House of Commons Hansard, 05 September 2016, Volume 614); en: https://hansard.parliament.uk/commons/2016-09-05/debates/1609058000001/EUReferendumRules.

47 Wells, A; «EU referendum: Remain lead at one» (YouGov UK, 6 June 2016), en: https://yougov. co.uk/news/2016/06/06/eu-referendum-remain-lead-one/ 
no sensacionalita, de menor tirada, como The Guardian, pero también The Times, y The Financial Times apoyaron la opción «remain» ${ }^{48}$. La BBC trató de mantener su tradicional, equilibrio y neutralidad, lo que, en parte resultó ser muy favorable para la agresiva y militante campaña de los partidarios de abandonar la UE.

En cambio, con respecto a los sectores económicos y finacieros — la city-, éstos apoyaron la opción «remain» en su conjunto — si bien con algunas excepciones- como ya habían hecho en 1975. En este sentido, en febrero de 2016, los presidentes y directores ejecutivos de casi un tercio de las empresas que forman parte del FTSE 100, el índice de las empresas británicas más grandes que cotizan en bolsa, firmaron una carta a favor de la permanencia del RU en la UE, señalando los peligros de la salida ${ }^{49}$.

En todo caso, el resultado del referéndum del 23 de junio de 2016, por muy sorprendente que fuese, aunque el margen de votos entre una y otra opción fuese muy reducido, aunque la sociedad británica se hubiese dividido por la mitad, en partes casi iguales, aunque supusiese dar un salto en el vacío de costes políticos, económicos y sociales impredecibles, aunque supusiese volver atrás en la Historia al punto de partida de 1972, no dejaba al Gobierno británico otra alternativa que activar el proceso de separación de la UE previsto en el Art. 50 del TUE. Y, desde luego, esta decisión del pueblo británico cancelaba el difícil y alambicado acuerdo conseguido en febrero de 2016 por el Primer Ministro David Cameron con los Jefes de Estado o de Gobierno de los demás Estados miembros de la UE.

\section{EL MARCO JURÍDICO DE LA SEPARACIÓN: EL ART. 50 DEL TEU}

\section{Las previsiones formales}

El RU, pues, decidió finalmente salir de la UE. Las consecuencias de su salida van a ser graves y van a afectar tanto al RU como a la propia UE. Es difícil predecir lo que va a ocurrir en el futuro y, desde luego, no es la intención de este

48 Véase un detallado análisis del papel de la prensa en la campaña del referéndum, en: Grant, C., "Why Britain Voted to Leave (If It Does...)», Policy brief, Centre for European Reform, London, 26 May 2016; y Grant, C.,, «How Leave Outgunned Remain: The Battle of the 'Five Ms'», Policy brief, Centre for European Reform, London, 25 June 2016.

49 Hellier, D. et al., «EU referendum: Top firms back pro-EU letter, but supermarkets refuse to sign», The Guardian, 23 February 2016; en: http://www.theguardian.com/politics/2016/feb/22. Y el descontento con el Brexit de un amplísimo sector económico y financiero británico se sigue manifestando aún hoy, largos meses después del referéndum. El 6 de julio de 2017, Carolyn Fairbairn, Directora General de la Confederation of British Industry (CBI), que representa a más de 190.000 empresas con más de 7 millones de empleados, pronunciaba una conferencia en la London School of Economics (LSE), en la que subrayaba la necesidad de una «smooth transition to a new EU deal» $\mathrm{y}$, para ello, la permanencia en el mercado interior tan amplia y duradera como fuere posible (FAIRBAIRn, C; NEWTON-SMiTh, R, «Eyes wide open: The importance of a smooth transition to a new EU deal», Confederation of British Industry - CBI, London School of Economics - LSE, London, 6 July 2017). En: http://www.cbi.org.uk. 
trabajo el hacer adivinaciones de ningún tipo. Lo que sí es cierto es que, tanto desde un punto de vista jurídico, como desde un punto de vista económico, pero también desde un punto de vista político y social, el Brexit va a traer consecuencias — las está trayendo ya — que van más allá de lo que los defensores de la salida del RU pensaban o, incluso, deseaban.

Desde un punto de vista jurídico, la decisión de un Estado miembro de abandonar la UE exige la activación de un procedimiento específico que está regulado en el Art. 50 del TEU. La dicción de este precepto no es verdaderamente muy precisa y deja algunos resquicios a la duda, o a la interpretación diferente. En todo caso, el procedimiento previsto en el Art. 50 del TEU, que se refiere también al apartado 3 del Art. 218 del TFUE y a la letra b) del apartado 3 del Art. 238 igualmente del TFUE, consta de las siguientes fases consecutivas:

a) Decisión de retirarse: Un Estado miembro de la UE puede decidir retirarse de la misma en cualquier momento, de acuerdo con sus propias previsiones constitucionales o legales. Aspecto éste en el que la UE no puede interferir en modo alguno. Ha de asumirse, sin embargo, que el Estado en cuestión se asegurará de que esas previsiones constitucionales o legales son observadas de manera estricta, de lo contrario, la decisión de salirse de la UE podría ser contestada jurídicamente en el orden interno y ello pondría en cuestión todo el proceso ${ }^{50}$. No exige el Art. 50 TUE que el Estado saliente haya de justificar esta decisión con fundamento en circunstancia excepcional alguna; y, de acuerdo con la Convención de Viena sobre el Derecho de los Tratados, de 1969 (Art. 42.2), basta con que decisión de retirarse se atenga a las disposiciones del propio tratado ${ }^{51}$. En este sentido, Closa entiende que la decisión de retirarse es «unilateral, unconditional and non-immediate», y Lippert y von Ondarza la definen como "fully sovereign and unilateral decisión» ${ }^{52}$.

Otra cuestión relevante que se planea aquí es si la decisión de retirarse de la UE supone también la retirada de la Comunidad Europea de la Energía Atómica (CEEA). Como es sabido, a diferencia de la Unión Europea creada por el Tratado de Maastricht en 1992, la Unión Europea resultante de las reformas del Tratado de Lisboa, de 2007, no comprende ya a la CEEA, que es regulada como una entidad separada e independiente de la UE. Sin embargo, a pesar de tratarse de personas jurídicas independientes, con su propio contenido material y competencial, la ilación entre ambas es muy estrecha y comparten el mismo marco institucional; y, en

50 En este sentido, Hillion, C., «Leaving the European Union, the Union way: A legal analysis of Article 50 TEU», European Policy Analysis, 8, 2016, pp. 2-3.

51 No es de aplicación aquí, pues, la previsión del Art. 62 de la Convención, que se refiere al «cambio fundamental en las circunstancias» como justificación de la denuncia unilateral o el incumplimiento de un tratado.

52 Closa, C., «Interpreting Article 50: Exit and voice and... what about loyalty?», EUI Working Paper, n 71, 2016, pp. 4 ss.; Lippert, B; von OndarZa, N., «Brexiting into Uncharted Waters», Stiftung Wissenschaft und Politik, SWP Comments, 35, July 2016, p. 2. 
lo que a la cuestión que aquí se trata se refiere, el Art. 106 bis del Tratado de la CEEA establece que se aplican a la CEEA una larga serie de artículos del TUE y del TFUE, entre los que se incluye específicamente el Art. 50 del TUE. En este sentido, si bien no se excluye jurídicamente la posibilidad de una salida de la UE manteniendo la adhesión a la CEEA, la articulación práctica de esta posibilidad se hace muy difícil, dado que las instituciones de gobierno de ambas entidades son las mismas. La lógica, pues, impone que una salida de la UE ha de llevar consigo también la salida de la CEEA $^{53}$.

b) Notificación: El Estado miembro que decida así salir de la UE debe notificar formalmente su intención al Consejo Europeo. Tampoco establece el Art. 50 TUE requisito alguno sobre cuál haya de ser la forma jurídica del acto de notificación; no obstante, la Convención de Viena sobre el Derecho de los Tratados exige que este tipo de notificaciones se haga por escrito (Art. 67.1).

Una cuestión importante que se plantea a este respecto es la posibilidad de que el Estado saliente decida retirar la notificación de su deseo de abandonar la UE, tras haberla presentado formalmente. El Art. 50 no prevé esta posibilidad, pero tampoco la excluye de manera expresa. En este sentido, no habría por qué excluir que un cambio - político o de otro tipo- en las circunstancias pudiese llevar al Estado en cuestión a revisar su voluntad de abandonar la UE. Y si eso fuese así, dada la voluntariedad de este proceso, no habría razón para impedir esta decisión. Muy al contrario, forzar al Estado en cuestión a mantenerse - en contra de su voluntad - en un procedimiento de salida de la UE que, además, tiene un término legal de dos años, a partir del cual «los Tratados dejarán de aplicarse al Estado de que se trate» (Art. 50.3 TUE), equivaldría de facto a una expulsión de la UE de ese Estado. Cabría aún plantear la duda sobre si habría un límite temporal, o procesal, a la posibilidad de la retirada de la notificación, y este límite bien pudiera ser el momento mismo del inicio de las negociaciones, dado que, a partir de ese momento, lo lógico es pensar que habría de estarse ya a lo que pudiera resultar de las mismas. El argumento sería que, a partir del inicio de las negociaciones, cualquier decisión que pudiera adoptar el Estado saliente incluida la decisión de retirarse de las negociaciones- es ya una parte de las mismas negociaciones y de su resultado. Se trataría así, además, de evitar cualquier tipo de manipulación del proceso por parte del Estado saliente, buscando dilaciones indebidas, etc. ${ }^{54}$. Posición ésta que yo mismo he mantenido en otro lugar ${ }^{55}$.

53 En similar sentido: Carmona, J.; Cirlig, C.; Sgueo, G., UK withdrawal from the European Union: Legal and procedural issues (Brussels: European Parliamentary Research Service, March 2017), p. 8; en contra: Brown, A., «Energy Brexit: Initial thoughts», International Energy Law Review, 5, 2016, pp. 209-221.

54 En este sentido, se sostiene la posibilidad de que esta revocación pudiese llegar a ser remitida al Tribunal de Justicia de la UE (vid. RenwiCK, A., «The pocess of Brexit: What comes next?», University College of London, UCL Working Paper, 2017, p. 33; CARMONA, J. et al., UK withdrawal, cit. p. 10). Otros sólo admiten la posibilidad de retirar la notificación en el caso de que el Estado en cuestión actúe de buena fé (vid. Craig, P., «Brexit: A Drama in Six Acts», European Law Review, 41:4, 2016, pp. 447-468.

55 Bar Cendón, A., "The UK, the EU and 'Brexit'», cit. 
Sin embargo, entiendo ahora que esta posición peca en exceso de procedimentalista y que el proceso de la negociación —y de la separación en su conjunto- es un proceso propiamente político que, si bien tiene un cauce jurídico para su sustanciación, nada impide una decisión política sobre la reversión del mismo, bien porque el Estado saliente decida volverse atrás de manera unilateral, bien porque así se acuerde por las dos partes, de manera conjunta ${ }^{56}$. De hecho, la Convención de Viena Sobre el Derecho de los Tratados admite la posibilidad de la retirada de una notificación del deseo de abandonar un tratado internacional (Art. 68).

c) Objeto de la negociación: Se inicia así un proceso de negociación entre la UE y el Estado saliente. Esta negociación se refiere primordialmente al acuerdo de separación («un acuerdo que establecerá la forma de su retirada», dice el Art. 50.2). Pero, el Art. 50.2 dice también, de una manera muy ambigua, que esta negociación se celebrará con ese Estado «teniendo en cuenta el marco de sus relaciones futuras con la Unión». Ello podría significar dos cosas: o bien que el acuerdo de separación puede incluir también previsiones referidas a las relaciones futuras entre la UE y el Estado en cuestión; o bien que el acuerdo de separación y el acuerdo sobre las relaciones futuras, aunque sean dos acuerdos diferentes y se formalicen en textos jurídicos separados, deberían ser negociados de manera simultánea o paralela; de otra manera, muy difícilmente el acuerdo de separación podría «tener en cuenta» el marco de las relaciones futuras entre las dos partes.

En términos estrictamente jurídicos, sin embargo, parece lógico que la negociación se separe en dos ámbitos diferentes y que su resultado figure en dos textos jurídicos diferentes —uno sobre los términos de la separación y otro sobre el contenido de las futuras relaciones UE-RU_-, y ello con independencia de si las negociaciones se realizan sobre estos ámbitos de manera simultánea o consecutiva. Y esto es así porque el régimen jurídico establecido por los Tratados para la conclusión de acuerdos sobre esos dos ámbitos es bien diferente: en primer lugar, el acuerdo de separación está regulado en el Art. 50 del TUE, mientras que el acuerdo sobre las relaciones futuras será un tratado internacional entre la UE y un Estado tercero, sometido a las previsiones generales de los Arts. 216 a 219 del TFUE y, en lo que se refiere a acuerdos comerciales, a las previsiones específicas que rigen la política comercial común, Arts. 206 y 207 del TFUE. En segundo lugar, el acuerdo de separación no exige en sí mismo una reforma de los Tratados,

56 A favor de la posibilidad de la retirada de la notificación se manifestó, de manera temprana: PIRIS, J-C., «Article 50 is not for ever and the U.K. could change its mind», Financial Times, September 1, 2016; luego, entre otros: BARTOLONE, C., «Rapport d'information sur les suite du referendum britanique et le suivi des negotiations», Assemblée Nationale, Mission d'Information, $\mathrm{n}^{\circ}$ 4485, 15 février, 2017; EECKHOUT P, FrantZiou E, «Brexit and Article 50 TEU: a constitutionalist Reading», UCL European Institute, Working paper, December 2016; Kreilinger, V., «Brexit: Negotiation phases and scenarios of a drama in three acts», Jacques Delors Institute, Policy Paper, 182, 25 January 2017. En España: Martín Pérez de Nanclares, J., «La Unión Europea ante el desafío del Brexit», cit. Sin embargo, el Tribunal Supremo británico ha rechazado esta posibilidad, como se analiza en detalle más adelante (caso Miller and Dos Santos $v$ Secretary of State, de 24 de enero de 2017, R [2017] UKSC 5). 
sin perjuicio de la recomposición de las instituciones y de los aspectos financieros y presupuestarios que puedan hacerse con posterioridad a la separación —que sí pueden requerir una reforma en algún caso-, pero ello no puede ser en modo alguno un componente de la negociación ni del acuerdo de separación entre las dos partes. En cambio, el acuerdo sobre las relaciones futuras es algo más abierto e indefinido, por lo que podría llegar a incluir cláusulas que supusiesen la necesidad de una reforma de los Tratados, aunque ello no sea tampoco algo imprescindible ni previsible. Y, en tercer lugar, el acuerdo de separación no requiere la ratificación de los demás Estados miembros de la UE: el Art. 50 TUE no lo prevé. Se trata de un acuerdo entre la UE y el Estado saliente, el cual, además, puede abandonar la UE, por una decisión soberana, haya o no acuerdo de separación en el plazo previsto de dos años. Las reformas que se puedan hacer en los Tratados con posterioridad a la salida del Estado en cuestión, en cambio, sí requieren la ratificación de todos los Estados miembros de la UE (Art. 48 TUE), como la requieren también determinado tipo de acuerdos internacionales concluidos por la UE con terceros Estados u organizaciones internacionales (Art. 218 TUE) $)^{57}$.

d) Orientaciones del Consejo Europeo: El Consejo Europeo debe adoptar unas «orientaciones» generales para guiar la actuación de la UE en las negociaciones correspondientes con el Estado saliente.

e) Autorización y recomendaciones del Consejo: El Consejo dirige la negociación y, en este sentido (de acuerdo con el Art. 218.3 TFUE): adopta la decisión por la que se autoriza la apertura de negociaciones; nombra al negociador, o jefe del equipo de negociación de la UE; y adopta las «directrices» precisas para la realización de las negociaciones. Directrices que son el resultado de las recomendaciones que ha de presentarle de manera previa la Comisión Europea (Art. 218.3 del TFUE).

f) La Comisión negocia: La Comisión Europea, a través de su representante y de su equipo negociador, es quien lleva a cabo las negociaciones con el Estado saliente. Las negociaciones han de ser conducidas - dentro del marco general establecido por las «orientaciones» emanadas por el Consejo Europeo- de acuerdo con las «directrices» más detalladas del Consejo. En realidad, estas directrices - como acabamos de ver- las adopta el Consejo con base en las recomendaciones que previamente ha de presentarle la propia Comisión, según lo previsto en el Art. 218.3 del TFUE.

g) Resultado de la negociación: El resultado de la negociación —el acuerdo de separación y, en su caso, el acuerdo sobre las futuras relaciones de la UE con el Estado saliente-, que ha de adoptar la forma jurídica de tratado internacional, ha de ser aprobado por el Consejo, que, de acuerdo con el Art. 218.2 del TFUE,

57 Véase un detallado análisis de las diferentes posibilidades de conformación de los acuerdos de la negociación en: Bartolone, C., «Rapport d'information», cit., p, 17 ss.; CARmona, J; et al., UK withdrawal, cit., p. 12 ss. 
«autorizará la apertura de negociaciones, aprobará las directrices de negociación, autorizará la firma y celebrará los acuerdos». En el caso de un acuerdo separado sobre las futuras relaciones de la UE con el Estado saliente, los términos formales de su conclusión están condicionados por el contenido que este acuerdo vaya a tener, pero, lo normal, dado que su contenido va a regir primordialmente las relaciones comerciales entre la UE y ese Estado, es que — como acabamos de ver- se formule según las previsiones específicas del Art. 207 del TFUE, referido a los acuerdos comerciales concluidos por la UE.

b) Conclusión del acuerdo: El Consejo, pues, es quien celebra el acuerdo final, en nombre de la Unión, por mayoría cualificada. La mayoría cualificada en este caso no es la ordinaria, sino la reforzada que establece la letra b) del apartado 3 del Art. 238 del TFUE. Es decir, se requiere «un mínimo del 72\% de los miembros del Consejo que represente a Estados miembros participantes que reúnan como mínimo el $65 \%$ de la población de dichos Estados». Y, desde luego, como establece el Art. 50.4 del TUE, el Estado miembro que se retira no puede participar ni en las deliberaciones ni en las decisiones del Consejo, o del Consejo Europeo, que le afecten.

i) Aprobación del Parlamento Europeo: El acuerdo de separación ha de ser aprobado por el Parlamento Europeo, de manera previa. El TUE no establece referencia específica alguna ni al procedimiento parlamentario ni a la mayoría requerida a este respecto, por lo que esta cuestión es regulada exclusivamente por el Reglamento interno del Parlamento Europeo (RPE). Así, de acuerdo con el RPE, las decisiones sobre la retirada de un Estado miembro de la Unión han de ser aprobadas por mayoría de los votos emitidos (Art. 82: Retirada de la Unión). El procedimiento del debate parlamentario se regula por el Art. 81 del RPE, el cual, a su vez, se refiere al Art. 99. Así, el RPE establece que, al término de las negociaciones, pero antes de la firma del acuerdo, éste ha de ser remitido al Parlamento para su aprobación (Art. 81.5 RPE); trámite de aprobación parlamentaria que es regulado en su detalle por Art. 99 RPE. Según este último precepto, el Parlamento Europeo ha de pronunciarse sobre el proyecto de acuerdo de separación en una sola votación, sin que se pueda presentar ninguna enmienda. Y, dado que los Tratados no establecen ninguna norma específica a este respecto, la mayoría necesaria para la aprobación será la mayoría de los votos emitidos. Si no se obtiene esta mayoría, el acuerdo de separación se considerará rechazado.

Al contrario de la precisión establecida por el Art. 50.4 del TUE con respecto a la participación de los representantes del Estado saliente en las deliberaciones del Consejo o del Consejo Europeo que le afecten, nada dice el Art. 50 TUE con respecto a la participación en las deliberaciones del Parlamento Europeo de los diputados elegidos en el Estado saliente, lo que, evidentemente, supone que no hay prohibición jurídica alguna. Otra cosa sería que, por exigibles motivos éticos — conflicto de intereses-, éstos se abstuviesen de participar en las deliberaciones referidas a este proceso de separación, o a cualquier otra cuestión que afectase sustantivamente al futuro de la UE; y, en este último caso, más bien 
por su falta de interés objetivo en el asunto, dado que poco debe importar cuál pueda ser el futuro de la UE a quien quiere salirse de ella.

j) Plazo: El plazo para concluir un acuerdo de separación es de dos años, a partir de la fecha de la notificación formal al Consejo Europeo por parte del Estado saliente de su intención de separarse de la UE. A partir de ese momento, o, en su caso, a partir de la fecha de la firma del acuerdo de separación, los Tratados dejarán de aplicarse al Estado saliente. Sin embargo, el Consejo Europeo, de acuerdo con dicho Estado, puede decidir — por unanimidad - prorrogar dicho plazo. No establece el Art. 50 TUE ningún límite temporal para la duración de esta prórroga, ni tampoco si se podría, o no, realizar prórrogas temporales sucesivas.

k) Reentrada: En fin, concluido todo este proceso, nada impide que un Estado miembro que se haya retirado de la UE pueda en el futuro solicitar de nuevo su adhesión. Pero, su solicitud de adhesión será tramitada a través del procedimiento ordinario establecido en el Art. 49 del TUE a estos efectos. No cabe, pues - los Tratados no lo prevén-, la reentrada automática de una antiguo Estado miembro tras su solicitud.

\section{La aplicación práctica}

Pero ¿cuál es la aplicación práctica que se ha hecho de estas previsiones formales en el caso de la separación del RU? Conviene aquí distinguir dos ámbitos diferentes: a) la adopción por el RU de la decisión de retirarse de la UE, y b) la actuación correspondiente de la UE.

\section{a) La decisión del Reino Unido de retirarse de la Unión Europea}

La activación del proceso de separación de la UE previsto en el Art. 50 del TUE se produjo el 29 de marzo de 2017, cuando el Gobierno británico presentó ante el Consejo Europeo una carta por la que notificaba formalmente su intención de abandonar la UE y también la CEEA ${ }^{58}$.

La decisión del Gobierno británico no fue fácil y estuvo plagada de obstáculos políticos y jurídicos. Es verdad que el Gobierno del RU no estaba jurídicamente obligado a iniciar el proceso de separación de la UE, en cumplimiento de la decisión del pueblo británico expresada en el referéndum del 23 de junio de 2016; y ello, porque de los términos de la European Union Referendum Act 2015 se deriva que el referéndum sobre la salida de la UE tenía un carácter meramente

58 Véase: Cameron, D., PM letter to President of the European Council Donald Tusk, London, 10 November 2015; en: https://www.gov.uk/government/uploads/system/uploads/attachment_data/file/475679/Donald_Tusk_ letter.pdf 
consultivo. El Gobierno británico, sin embargo, tanto antes como después del referéndum, adoptó una posición muy clara a este respecto, manifestando su decisión de cumplir con el mandato político que surgiese de las urnas, con independencia de cuál fuese la diferencia de votos entre una u otra opción ${ }^{59}$. Y la nueva Primera Ministra, Theresa May, lo dejó muy claro también en su primera sesión de preguntas en el Parlamento, el 20 de julio de 2016: «I am very clear that Brexit does mean Brexit» ${ }^{60}$.

Pero, habiendo asumido el compromiso de aplicar el resultado del referéndum hasta sus últimas consecuencias, otro de los aspectos que resultaron inicialmente problemáticos fue la cuestión de si Gobierno británico requería, o no, la previa autorización del Parlamento para iniciar el proceso de separación; y, por lo tanto, si el Parlamento podía llegar a bloquear —o, cuando menos, dilatar en el tiempo- el proceso de separación, movido por los votos de los diputados opuestos al Brexit. El argumento podía ser político en el fondo, pero tenía una verdadera relevancia jurídico-constitucional. La cuestión era que — de acuerdo con la visión mayoritaria de los constitucionalistas británicos- la adhesión a las CCEE, primero, y a la UE después, había sido aprobada por una ley del Parlamento — la European Communities Act 1972, reformada varias veces con posterioridad-y la supremacía normativa del Parlamento supone que sólo el Parlamento puede revocar una decisión adoptada por ley del Parlamento: «legislation can only be altered by legislation ${ }^{61}$. Además, a ello debería añadirse el hecho de que la constitución de los nuevos territorios autónomos de Irlanda del Norte, Escocia y Gales planteaba la duda de si también las asambleas legislativas de los mismos debían ser igualmente consultadas antes de activar el Art. 50, como sostenían el Lord Advocate del Gobierno de Escocia y el Counsel General del Gobierno de Gales. El Gobierno británico, sin embargo, quiso evitar un posible bloqueo parlamentario y, para ello, interpretó que la acción de activar el procedimiento del Art. 50 del TUE era

59 Véase Cameron, D., «Statement by the Prime Minister at the House of Commons on the UK's new special status in the EU and the in-out referendum on 23 June». The Prime Minister's Office, 10 Downing Street, and The Rt Hon David Cameron MP. Delivered on: 22 February 2016; en: https://www.gov.uk/ government/speeches/pm-commons-statement-on-eu-reform-and-referendum-22-february-2016; y CAMERON, D, «Statement made by the Prime Minister David Cameron in Downing Street on the outcome of the referendum on the UK's membership of the European Union». Prime Minister's Office, 10 Downing Street, and The Rt Hon David Cameron MP. Delivered on: 24 June 2016; en: https://www.gov.uk/government/ speeches/eu-referendum-outcome-pm-statement-24-june-2016.

60 May, T., Prime Minister's Questions in the House of Commons on Wednesday 20 July 2016 (House of Commons, Commons Chamber, Oral Answers to Questions, Prime Minister, Hansard, 20 July 2016, Vol. 613; en: https://hansard.parliament.uk/commons/2016-07-20/debates/16072025000019/Engagements.

61 Barber, N. et al., Pulling the Article 50 'Trigger': Parliament's Indispensable Role (London: UK Constitutional Law Association, 27 June 2016). El 9 de julio de 2016, más de mil juristas británicos — de ellos, 100 Queen's Counsels_ dirigieron una carta al Parlamento y al Gobierno solicitando que, dado que el referéndum era meramente consultivo y que se había proporcionado una información distorsionada a los ciudadanos, el Parlamento adoptase una decisión fundamentada sobre la cuestión, ignorando su resultado. (Véase el texto completo de la carta en: http://www.independent.co.uk/news/uk/politics/brexit-eu-referendum-result-not-legally-binding-lawyers-letter-a 7129626.html). 
un trámite de carácter político o ejecutivo (perteneciente al ámbito de los «prerogative powers» de la Corona, que ejerce autónomamente el Gobierno), como el inicio de la negociación de cualquier tratado internacional, y que, por lo tanto, no requería la previa aprobación del Parlamento. A mayor abundamiento, entendía el Gobierno británico que el párrafo 2 de la Sección 2, de la European Communities Act 1972 — que regula los aspectos fundamentales de la pertenencia del RU a la UE- le habilitaba para adoptar cualquier tipo de previsión jurídica destinada a la aplicación de esta Ley del Parlamento, incluida, por supuesto, la decisión de activar el procedimiento de separación previsto en el Art. 50 del TUE ${ }^{62}$.

La cuestión fue finalmente llevada a los tribunales que, en dos sentencias consecutivas, primero la High Court of Justice, Queen's Bench Division, Divisional Court, de Londres (judgement Miller and Dos Santos $v$ Secretary of State, de 3 de noviembre de 2016), y luego, en apelación, el Tribunal Supremo (Supreme Court judgment Miller and Dos Santos v Secretary of State, de 24 de enero de 2017, $\mathrm{R}$ [2017] UKSC 5) ${ }^{63}$, entendieron que la activación del procedimiento del Art. 50 del TUE por parte del Gobierno británico requería la autorización previa del Parlamento, a través de una ley. Y ello, porque —entendió el Tribunal Supremo- la actuación del Gobierno en esta cuestión no era un mero acto ejecutivo, de prerrogativa — «prerogative power»— que no afectaba a la legislación ordinaria, ni tampoco podía el Gobierno acudir a la potestad atribuida por la Sección 2 de la European Communities Act 1972, dado que esta se refiere a la participación del Gobierno en el proceso de formulación del Derecho de la UE, mientras que el procediemiento de separación del Art. 50 TUE se refiere justamente a lo contrario: a poner fin a ese proceso (parágrafo 95). En la visión del Tribunal, pues, la decisión de salirse de la UE produce cambios fundamentales en la estructura constitucional y legislativa del RU, al cortar de raíz la fuente del Derecho de la UE (parágrafos 78-80), y tales cambios son la consecuencia necesaria de la decisión de activar el procedimiento del Art. 50 del TUE (parágrafo 81). Y, desde luego, los cambios constitucionales sólo pueden efectuarse por legislación del Parlamento (parágrafo 82). A mayor abundamiento - concluye el Tribunal Supremo-, el referéndum de 2016 tiene un gran significado político, sin embargo, su significado jurídico — que es sobre lo que el Tribunal ha de pronunciarse - está determinado por lo que el Parlamento decidió incluir en la ley que lo autorizó, la European Union Referendum Act 2015, y esta ley simplemente establece cómo ha de celebrarse el referéndum, pero no especifica

62 El párrafo 2 de la Sección 2, de la European Communities Act 1972 —aún en vigor- establece que "any designated Minister or department may by order, rules, regulations or scheme, make provision [...] for the purpose of implementing any obligation of the United Kingdom, or enabling any such obligation to be implemented, or of enabling any rights enjoyed or to be enjoyed by the United Kingdom under or by virtue of the Treaties to be exercised».

63 Supreme Court Judgement $R$ (on the application of Miller and another) $v$ Secretary of State for Exiting the European Union [2017] UKSC 5, de 24 de enero de 2017; en: https://www.supremecourt.uk/cases/docs/uksc2016-0196-judgment.pdf. 
cuáles han de ser las consecuencias de este referéndum. Sólo una ley del Parlamento, pues, puede modificar o desarrollar este aspecto y determinar cuáles hayan de ser las consecuencias del referéndum (parágrafos 116-124). Por otra parte, en lo que se refiere al poder de las asambleas legislativas de los territorios autónomos - devolved legislatures - y a la hipotética necesidad de consultarlas previamente sobre esta cuestión, entiende el Tribunal que los estatutos de autonomía de los territorios - devolution Acts - fueron aprobados por el Parlamento en la asunción de que el RU era miembro de la UE, pero ello no exige que el RU se mantenga como miembro de la UE. En este sentido, las relaciones con la UE y, en general, los asuntos exteriores están reservados al Parlamento y al Gobierno y, por ello, la decisión sobre la retirada de la UE sólo corresponde al Parlamento (parágrafos 129-130). Las devolved legislatures, pues, carecen de poder de veto sobre la decisión del RU de retirarse de la UE (parágrafo 150) ${ }^{64}$.

Por otra parte, esta transcendente sentencia del Tribunal Supremo británico vino también a cerrar de manera definitiva otro aspecto muy discutido, tanto en ámbitos académicos y jurídicos, como en ámbitos políticos, y al que hemos hecho referencia en páginas anteriores: la posibilidad de la retirada de la notificación de la decisión del RU de salirse de la UE. El alto Tribunal entiende que esta notificación «no puede ser presentada en términos cualificados o condicionales y que, una vez presentada, no puede ser retirada» (parágrafo 26) ${ }^{65}$; con lo que el debate sobre esta cuestión debe considerarse cerrado: el RU, pues, por su propia voluntad, está irremediablemente abocado a su salida de la UE.

En cumplimiento de la sentencia del Tribunal Supremo, el Gobierno de Theresa May presentó al Parlamento, el 26 de enero de 2017, un proyecto de ley para autorizar al Gobierno a activar el procedimiento previsto en el Art. 50 del TUE (European Union (Notification of Withdrawal) Bill 2017). Para ello, se siguió el procedimiento abreviado, lo que hizo que el proyecto fuese tramitado directamente en el pleno de las cámaras, sin pasar previamente por el debate en comisión. La Cámara de los Comunes aprobó el Proyecto por amplia mayoría (494 a favor, 122 en contra) el 8 de febrero, y la Cámara de los Lores lo aprobó el 6 de marzo, pero con dos importantes enmiendas: la primera pretendía asegurar el

64 De manera más específica, en lo que se refiere a Escocia, entiende el Tribunal Supremo que tampoco es de aplicación aquí la denominada Sewel Convention, de 1998, según la cual el Parlamento británico se compromete a consultar previamente al Parlamento escocés cuando haya de adoptar una decisión que afecte a competencias transferidas a Escocia. Y ello, porque — considera el Tribunal — se trata sólo de una convención política cuya aplicación no está sometida al control de los jueces: «The Sewel Convention has an important role in facilitating harmonious relationships between the UK Parliament and the devolved legislatures. But the policing of its scope and the manner of its operation does not lie within the constitutional remit of the judiciary, which is to protect the rule of law». (parágrafo 151).

65 Traducción propia. En sus mismos términos, entiende el Tribunal «that notice under article 50(2) [...] cannot be given in qualified or conditional terms and that, once given, it cannot be withdrawn». A lo que añade, en términos muy explícitos: "It follows from this that once the United Kingdom gives Notice, it will inevitably cease at a later date to be a member of the European Union and a party to the EU Treaties». 
respeto de los derechos de los ciudadanos europeos residentes en el RU tras la separación ${ }^{66}$; y la segunda exigía que el Primer Ministro no pudiese concluir el acuerdo de separación de la UE sin la autorización previa del Parlamento. ${ }^{67} \mathrm{La}$ Cámara de los Comunes, sin embargo, rechazó las dos enmiendas de los Lores el 13 de marzo, lo que hizo que el proyecto tuviese que volver a la Cámara de los Lores. Los Lores, sorprendentemente y con gran prontitud, se desdijeron de su anterior decisión y, el mismo día 13 de marzo, aprobaron el proyecto como inicialmente se lo habían remitido los Comunes; proyecto que, tras la promulgación regia, pasó a convertirse en la European Union (Notification of Withdrawal) Act 2017 (c. 9), de 16 de marzo de 2017. El Gobierno recibía así prácticamente la carta blanca del Parlamento para negociar la separación con la UE, dado que, al haber sido rechazadas las dos enmiendas de los Lores, ni se requiere ahora la previa autorización del Parlamento para concluir el acuerdo —en todo caso, sólo una vez concluido éste- - ni los derechos de los ciudadanos europeos residentes en el RU quedan ahora fuera de la negociación (y, de hecho, éste es uno de los temas importantes que el RU pretende utilizar como moneda de cambio en las negociaciones con la UE).

Así, recibida la autorización del Parlamento, la Primera Ministra, Theresa May, presentó al Consejo Europeo la carta de notificación del deseo del RU de retirarse de la UE y también de la CEEA el 29 de marzo de 2017. De esta manera se iniciaba formalmente el procedimiento de separación previsto en el Art. 50 del TUE. Sin embargo, no faltaron voces en el RU que pretendieron entonces $-\mathrm{y}$ lo hacen aún ahora - una revocación de la decisión de activar el procedimiento del Art. 50 TUE. Como hemos visto en páginas anteriores, es difícil argumentar jurídicamente en contra de esta posibilidad. Se trata de un proceso sustantivamente político — bien que articulado en términos jurídicos — que está sometido a decisiones y circunstancias políticas. Y, de hecho, las circunstancias políticas han cambiado en el RU con posterioridad a la presentación formal de la notificación que inició el procedimiento de salida ${ }^{68}$. ¿Por qué, pues, impedir la posibilidad de que se

66 En sus pripios términos, la enmienda pretendía «to ensure that citizens of another European Union or European Economic Area country and their family members, who are legally resident in the United Kingdom on the day on which this Act is passed, continue to be treated in the same way with regards to their EU derived-rights». (Vid.: https://services.parliament.uk/bills/2016-17/europeanunionnotificationofwithdrawal/stages.html).

67 La enmienda requería que «the Prime Minister may not conclude an agreement with the European Union under Article 50(2) of the Treaty on European Union, on the terms of the United Kingdom's withdrawal from the European Union, without the approval of both Houses of Parliament». (Vid.: https://services.parliament.uk/bills/201617/europeanunionnotificationofwithdrawal/stages.html).

68 El 8 de junio de 2017, se celebraron en el RU unas elecciones generales convocadas por sorpresa por la Primera Ministra May, cuando le quedaban aún tres años — más de la mitad— de su mandato por cubrir, con la intención de ampliar su ya muy amplia mayoría parlamentaria y con un doble objetivo: reforzar su respaldo político ante la negociación del Brexit y reducir aún más el papel político de la oposición, aprovechándose de la debilidad del discutido líder del partido laborista, Jeremy Corbyn. Sin embargo, el resultado no pudo haber sido más desastroso: May y el partido conservador perdieron la mayoría absoluta de la que disfrutaban desde las elecciones de 2015 y afrontan desde entonces la necesidad de 
pueda revertir un resultado que se anuncia y se prevé muy gravoso para las dos partes — la UE y el RU—, en términos políticos, económicos y sociales?

Así pues, la carta del Gobierno británico del 29 de marzo de 2017 puso en marcha el procedimiento previsto en el Art. 50 del TUE. A partir de este momento, si bien el RU sigue siendo un miembro de la UE, no lo es ya a todos los efectos. Desde luego, en términos jurídicos, el RU ya no podrá participar «ni en las deliberaciones ni en las decisiones del Consejo Europeo o del Consejo que le afecten», como establece el párrafo 4 del Art. 50 del TUE; y, en términos políticos, el RU no es ya un socio más de la UE, sino un Estado que negocia con la UE — como si se tratase de un Estado tercero- su separación y su futuro y, en esa negociación, ambas partes van a defender sus respectivos intereses, que no van a ser necesariamente coincidentes y, desde luego, no en todos los $\operatorname{casos}^{69}$.

\section{b) La respuesta de la Unión Europea}

La posición de la UE en este proceso de separación del RU viene marcada por una larga serie de documentos que se han ido emitiendo por las instituciones de la Unión desde el momento mismo en el que se produjo el referéndum del 23 de junio de 2016. Sin embargo, los documentos más importantes y que aquí interesan son los que se han formulado en aplicación de las previsiones específicas que regulan el procedimiento del Art. 50 del TUE, tal y como fueron detalladas en páginas anteriores; es decir: a) las orientaciones del Consejo Europeo, que fueron aprobadas el 29 de abril de $2017^{70}$; b) las recomendaciones de la Comisión al Consejo, para que adopte una decisión autorizando la apertura de negociaciones y designe al negociador, de 3 de mayo ${ }^{71}$; y c) la decisión del Consejo autorizando

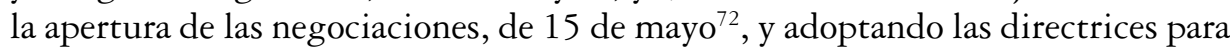

tener que formar un Gobierno minoritario con el apoyo parlamentario de los 10 diputados del ultraconservador y eurófobo Democratic Unionist Party (DUP) de Irlanda del Norte. En este caso, sin embargo, no parece que el resultado electoral vaya a determinar un cambio en la posición del RU con respecto al Brexit, pero sí puede influir en la orientación que vayan a tener las negociaciones con la UE.

69 «Cualquier acuerdo que se alcance con el Reino Unido como país tercero deberá basarse en un equilibrio entre derechos y obligaciones», decía la Declaración aprobada en la Reunión informal de los Veintisiete, en Bruselas, el 29 de junio de 2016, tras el referéndum (Reunión informal de los Veintisiete, Declaración, Bruselas, 29 de junio de 2016; en: http://www.consilium.europa.eu/es/press/press-releases/2016/06/29-27ms-in formal-meeting-statement

70 Consejo Europeo, Reunión extraordinaria del Consejo Europeo (art. 50) (29 de abril de 2017) - Orientaciones (Bruselas, 29 de abril de 2017 (OR. en), EUCO XT 20004/17, BXT 10, CO EUR 5, CONCL 2).

71 Comisión Europea, Recomendación de Decisión del Consejo por la que se autoriza a la Comisión a entablar negociaciones para la celebración de un acuerdo con el Reino Unido de Gran Bretaña e Irlanda del Norte en el que se establecen las modalidades de su retirada de la Unión Europea (Bruselas, 3.5.2017, COM(2017) 218 final).

72 Consejo de la Unión Europea, Decisión del Consejo por la que se autoriza la apertura de negociaciones con el Reino Unido de Gran Bretaña e Irlanda del Norte relativas a un acuerdo en el que se establecen las modalidades de su retirada de la Unión Europea (Bruselas, 15 de mayo de 2017 (OR. en), XT 21016/17, BXT 24). 
la negociación, de 22 de mayo ${ }^{73}$. A ellos debe ser añadida $d$ ) la resolución del Parlamento Europeo, de 5 de abril de 2017, sobre las negociaciones con el Reino Unido $^{74}$, y también $e$ ) los — hasta ahora- 18 documentos temáticos formulados por la Comisión Europea, en desarrollo de estas directrices estratégicas ${ }^{75}$.

Sin embargo, en este trabajo - como se ha visto- nos ocupamos sólo de las consecuencias inmediatas que el Brexit trae consigo, en lo que se refiere a la activación del proceso de separación previsto en el Art. 50 del TUE, y lo hemos hecho tanto desde un punto de vista jurídico, como político. No se trata aquí, pues, de analizar en detalle el proceso negociador que acaba de comenzar ${ }^{76}$, ni tampoco se trata de analizar los posibles contenidos del acuerdo de separación ni del acuerdo sobre las futuras relaciones UE-RU, ni, desde luego, las consecuencias que el Brexit pueda tener, tanto para el RU como para la UE. Son todos ellos aspectos del problema de extraordinaria relevancia, pero se trata de ámbitos y perspectivas que exceden con mucho las propias de este trabajo y del marco general de la publicación en la que se integra ${ }^{77}$.

\section{CONCLUSIÓN}

El RU ha decidido retirarse de la UE. En realidad, de acuerdo con los datos expuestos en este trabajo, quizá nunca debió haber entrado. Consideraciones utilitarias, sin embargo, llevaron al RU a solicitar la entrada en las CCEE primero, y a mantenerse en la UE después. El RU siempre pensó que, una vez dentro, podría modificar los planteamientos básicos de las CCEE y de la UE adaptándolos a sus propios intereses. Como decía Harold Wilson en 1967, de manera explícita: «el Tratado de Roma ... no es necesariamente un obstáculo si logramos que nuestros problemas sean resueltos satisfactoriamente, bien a través de adaptaciones de las previsiones del Tratado, bien de cualquier otra manera»; adaptaciones que

73 Consejo de la Unión Europea, Directrices de negociación de un acuerdo con el Reino Unido de Gran Bretaña e Irlanda del Norte en el que se establecen las modalidades de su retirada de la Unión Europea. ANEXO de la Decisión (UE, Euratom) 2017/... [15.5.2017] del Consejo por la que se autoriza la apertura de negociaciones con el Reino Unido de Gran Bretaña e Irlanda del Norte relativas a un acuerdo en el que se establecen las modalidades de su retirada de la Unión Europea (Bruselas, 22 de mayo de 2017 (OR. en) XT 21016/17, ADD 1 REV 2, BXT 24).

74 Parlamento Europeo, Resolución del Parlamento Europeo, de 5 de abril de 2017, sobre las negociaciones con el Reino Unido a raíz de la notificación por la que declara su intención de retirarse de la Unión Europea (2017/2593(RSP)).

75 Véanse estos documentos — «position papers»— en: https://ec.europa.eu/commission/brexit-negotiations/negotiating-documents-article-50-negotiations-united-kingdom_en.

76 La primera reunión formal de los equipos negociadores de la UE, presidido por Michel Barnier European Commission's Chief Negotiator-, y del RU, presidido por David Davis — Secretary of State for Exiting the European Union-, tuvo lugar en Bruselas, el 19 de junio de 2017.

77 De las negociaciones entre la UE y el RU y de su posible resultado —el acuerdo de separación y el acuerdo sobre las futuras relaciones UE-RU- nos ocupamos en otro trabajo que verá la luz en el siguiente número de esta revista. 
"pueden realizarse mejor tras nuestra entrada» ${ }^{78}$. No sé si puede decirse que esta perspectiva era malintencionada, pero, desde luego, fue una perspectiva equivocada — como el resultado del referéndum de junio de 2016 demuestra-, dado que ni el RU logró nunca adaptar plenamente la UE a sus intereses, ni la UE ha logrado llevar adelante su proceso de integración en los términos que habían sido inicialmente diseñados. Esto ha hecho — como se ha visto en las páginas anteriores- que las relaciones RU-UE hayan sido siempre difíciles y que, si bien desde muchos puntos de vista el balance de esta relación es muy positivo, la presencia del RU en la UE, sin embargo, ha sido siempre un pesado lastre, un freno al proceso de integración política y económico de Europa.

En este sentido, para la UE, la salida del RU puede ser una nueva oportunidad para replantearse el proceso de integración y para llevarlo adelante, quizá de una manera diferente, pero sí de una manera más rápida y decidida. Para el RU, en cambio, se abren unas expectativas que quizá no sean tan positivas como los defensores del Brexit han previsto, o desean. Lo importante, en todo caso, es determinar cuál y cómo va a ser la nueva relación del RU con la UE tras la separación. Las opciones para la articulación de esa relación son muchas y muy amplias, y han sido ya detalladamente descritas y analizadas por la doctrina. No es ésta, sin embargo, la materia de la que nos ocupamos es este trabajo, pero es evidente que el acuerdo final ha de definir unas relaciones que van a ser - han de ser - necesariamente diferentes y mucho más estrechas que las que hasta ahora se han definido en los diferentes acuerdos de la UE con otros Estados. Casi 45 años de existencia en común no pueden ser borrados de un plumazo sin producir un grave daño, tanto a la UE como al RU. Y, desde luego, entiendo que no es eso lo que se quiere, ni siquiera por parte de quienes han provocado la dramática decisión de la salida del RU de la UE.

TITLE: The United Kingdom and the European Union: Beginning and end of a troubled relationshi

ABstract: Almost 45 years after joining the European Communities, the United Kingdom has decided to leave the European Union following the referendum of June 2016. Throughout its membership, the two have shared a difficult relationship and despite there having been a very positive dimension for both sides, it is impossible to ignore the negative dimension. This article intends to describe and analyse how this process has taken place and how the relationship of the U.K. with the EECC and the E.U., evolved since the U.K.'s first application to join the EECC was submitted, in 1961, until the starting of the negotiations for the withdrawal in June 2017.

Resumen: Cuando estaba a punto de cumplirse el 45 aniversario de su ingreso en las Comunidades Europeas, el Reino Unido decidió salir de la Unión Europea mediante el referéndum de junio de 2016. Entre un momento y otro ha habido una relación difícil; relación que ba tenido una dimensión muy positiva para

78 Traducción propia del original inglés: WiLsON, H., «Statement by Harold Wilson on the United Kingdom's application for membership to the EC» (House of Commons, 2 May 1967), en: http://www.cvce.eu. 
las dos partes, pero también una dimensión negativa. Este trabajo trata de describir y analizar cómo se ha producido este proceso de relación del RU con las CCEE y con la UE, desde la solicitud de adhesión del $R U$, en agosto 1961, hasta el comienzo de las negociaciones sobre la separación de la UE, en junio de 2017.

KEY wORDS: United Kingdom, European Union, Brexit, withdrawal, referendum, opting-out, Treaty on the European Union, Treaty on the Functioning of the European Union.

Palabras Clave: Reino Unido, Unión Europea, Brexit, separación, referéndum, opting-out, Tratado de la Unión Europea, Tratado de Funcionamiento de la Unión Europea..

FECHA DE RECEPCIÓN: 14.06.2017

FECHA DE ACEPTACIÓN: 26.07.2017 